\title{
Individualist and Collectivist Orientations \\ in Verbal-Visual Persuasive Styles: \\ A Study of ENACTUS PowerPoint Presentations
}

\author{
Hala Tawfik Sorour Maklad \\ Sadat Academy for Management Sciences, \\ Department of Language
}

\begin{abstract}
The study addresses two questions related to the impact of ENACTUS as a global youth organization on breaking down cultural stereotypes; and the mediating role of its values in influencing the national 'Individualist' and 'Collectivist' cultures as reflected in the verbal and visual persuasion styles of Egyptian and American students. In the light of Collectivism-Individualism Dimension (Hofstede, 1991), three persuasive styles are examined: (a) Presentational style, (b) Analogical style, and (c) Quasi-Logical style (Johnstone, 1989). The data of the study is derived from two PowerPoint presentations delivered by teams of University students representing ENACTUS USA and Egypt in the World Cup Competition of 2012. The data analyzed are two synchronized components of the presentation: the verbal spoken utterances, and the visual synchronized slides. To unveil the verbal persuasive styles, the study draws mainly on Ungerer's Emotional Inferencing Principles (1997), Carter and McCarthy (2006), Biber, et al. (2007), and Hyland's approach to Engagement (2005). As for visual persuasive styles, reference is made to Kress and Leeuwen's visual systems of Representational, Interpersonal and Compositional Meanings (2006), and to the Intersemiotic Texture approach of Liu and O'Halloran (2009). Among the main findings of the study is that a mixture of individualist and collectivist orientations has been demonstrated in the verbal and visual persuasive styles of Egyptian and American teams. It has been verified that ENACTUS has played an effective role in building bridges between cultures through introducing new values into national cultures, creating a unique discursive interculture.
\end{abstract}

Key words: Individualism; Collectivism; Persuasive Styles; PowerPoint Presentations; Interculture.

\section{Introduction:}

During the past two decades, several global youth organizations such as ENACTUS (http://enactus.org), TEDX (https://www.ted.com), and AISEC (http://aiesec.org) have emerged and spread all over the world, bringing new values and communication patterns to national communities, and giving rise to the so-termed 'interculture'. Human 
communication, whether verbal or non-verbal, can be regarded as a "process with two extreme ends: intracultural end and intercultural end". However, it is maintained that there is a continuum rather than a dichotomy as "communicators are always in between, closer or further to one of the ends creating and interpreting meaning by using their existing linguistic tools" (Kecskes, 2015, pp.171-2). Along this continuum is interculture: "ad hoc creations" where cultural norms and patterns brought "from prior experience of interlocutors, blend with features created ad hoc in the interaction ..." (Kecskes, 2015, p.184).

Based on the assumption that ENACTUS may represent such an interculture, the study aims to investigate whether the youth organization values have mediated the influence of national 'Individualist' and 'Collectivist' cultures on persuasion styles to create such an ad hoc entity. To this end, the verbal and visual components of two PowerPoint presentations, delivered by national teams of Egypt and USA in ENACTUS world cup competition, are analyzed to account for persuasive styles. Reflecting the values of Individualism and Collectivism, ' $\boldsymbol{E N} \boldsymbol{A} \boldsymbol{C T U S}$ ' as an acronym stands for (http://enactus.org):

ENtrepreneurial - having the perspective to see an opportunity and the talent to create value from that opportunity;

ACTion - the willingness to do something and the commitment to see it through even when the outcome is not guaranteed;

US - a group of people who see themselves connected in some important way; individuals that are part of a greater whole.

\subsection{Individualism-Collectivism Dimension and Communicative Styles}

GudyKunst, Matsumoto, Ting-Toomey, Nishida, Kim \& Heyman contended that communicative styles "vary across cultures and within cultures" (1996, p. 511). One way to explain these variations is Individualism-Collectivism Dimension (I-CD), one of the national cultural dimensions ${ }^{1}$ suggested by Hofstede $(1991 ; 2001)$ to measure the

' Other dimensions are Power Distance, Masculinity, Uncertainty Avoidance, Indulgence, and Long Term Orientation. 


\section{Hala Tawfik Sorour Maklad}

degree of Dependence on others. As societal not individual characteristic, I-CD "is the degree to which people in a society are integrated into groups" (Hofstede 2011, p. 11). This dimension addresses the issue of "whether people's self-image is defined in terms of "I" or "we" (https://geert-hofstede.com/national-culture.html). On one side of the scale, there is the individualist culture "in which the ties between individuals are loose: everyone is expected to look after him/herself and his/her immediate family". On the other side is the collectivist culture "in which people from birth onwards are integrated into strong, cohesive ingroups ..." (Hofstede 2011, 11). This dimension in particular has been chosen for being related to ENACTUS values that cherish entrepreneurship and empowerment.

Comparing Egypt and USA through Hofstede's dimension of Individualism (https://geert-hofstede.com), it is found that :

a- Egypt, with a score of 25, is described as a collectivistic society, manifested in a close long-term commitment to the member 'group', whether a family, extended family, or extended relationships.

b- USA, with a score of 91, is considered one of the most Individualistic countries in the world. The society is "loosely-knit in which the expectation is that people look after themselves and their immediate families only and should not rely on authorities for support."

Briefly, in Hofstede's terms, Egypt and USA are placed at the extreme ends on I-CD scale

Egypt (25)

USA (91)

Collectivist cultures

Individualist

Cultures

The relation of I-CD and communication styles have been addressed by several scholars (e.g. Gudykunst, et al 1996; García-Yeste, 
2013; and Hofstede, 2015). Described by Hofstede as 'software of communication' (2015, p.1), communicative style refers to the various patterns of interaction that individuals learn when socializing, based on "the norms, rules, and values of their culture" (Gudykunst et al, 1996, p.510). The study defines communicative style as being related to (a) the verbal and para-verbal means by which one interacts, (Gudykunst et al, 1996, p. 511), and (b) "expectations about what is considered the proper or logical way to organize the presentation of ideas" (Lustig \& Koester 2003, p. 243).

As summarized in table (1), Hofstede (2015, p. 5) compared the communicative styles adopted in the Individualist and Collectivist societies, where the unmarked in the former are reference to independent self and distinctive personality, coding verbally direct explicit messages a main feature of low-context cultures; and in the latter are reference to interdependent self, in-group membership, seeking harmony, coding verbally indirect, implicit messages - a main feature of high-context cultures.

\begin{tabular}{|l|l|}
\hline Individualist societies & Collectivist societies \\
\hline $\begin{array}{l}\text { - "I", independent self / } \\
\text { - Direct, personal, verbal } \\
\text { - An honest person speaks } \\
\text { his/her mind } \\
\text { - Low-group } \\
\begin{array}{l}\text { communication: Lonterdependent self /Member of } \\
\text { everything should be } \\
\text { explicit }\end{array}\end{array}$ & $\begin{array}{l}\text { - Harmony should be preserved, direct } \\
\text { confrontations avoided } \\
\text { - High-context communication: many } \\
\text { things are implicit }\end{array}$ \\
\hline
\end{tabular}

Table: (1) I-CD in relation to communication styles (Hofstede, 2015, p.5)

The concept of context has been useful for understanding differences in communication across cultures since it explains the degree of directness of communication (Hall 1981). In a high-context culture "most of the information is either in the physical context or internalized in the person", and remains to a great extent indirect and implicit; while in a low-context culture, information is conveyed in the "explicit code" of 
the message (Hall, 1981, p.91). People of collectivist high-context cultures are expected to use symbols, signs, and indirect communication, and process information in a different way than people of individualist low-context cultures who are more oriented toward facts, explanations, and rhetoric (de Mooij, 2014, p. 229).

Cultural variation in communication has also been accounted for through the model of Persuasive Styles (Johnstone, 1989). Within this model, persuasive style is defined as the choices made by a persuader in a cross-cultural rhetorical context from a range of persuasive strategies. Johnstone (1989) presented three general strategies of persuasion that can form a culture's preferred style: Quasi-logical, Presentational and Analogical (summarized in table 2). Johnstone reiterated that such persuasive styles are "cultural predispositions" rather than "cultural rules" (1989, p.154). Emphasizing the linguistic and conceptual correlates of these strategies, Johnstone referred to "the historical and cultural givens that can predispose one or another persuasive strategy to become the dominant strategy of a particular group or that group's persuasive style". (1989, p.150)

\begin{tabular}{|l|l|l|l|}
\hline & Quasi-Logical & Presentational & Analogical \\
\hline $\begin{array}{l}\text { Distinguishing } \\
\text { model }\end{array}$ & $\begin{array}{l}\text { Model is taken from } \\
\text { formal logic; } \\
\text { convincing }\end{array}$ & $\begin{array}{l}\text { Model is taken from poetry; } \\
\text { moving }\end{array}$ & $\begin{array}{l}\text { Model is taken } \\
\text { from narrative; } \\
\text { teaching }\end{array}$ \\
\hline $\begin{array}{l}\text { Linguistics } \\
\text { correlates }\end{array}$ & $\begin{array}{l}\text { Use of logical } \\
\text { connectives: thus, } \\
\text { hence, therefore }\end{array}$ & $\begin{array}{l}\text { Rhetorical deixis: here, } \\
\text { now, this }\end{array}$ & $\begin{array}{l}\text { Formulaic } \\
\text { language: you } \\
\text { know what they } \\
\text { say }\end{array}$ \\
\cline { 2 - 4 } & $\begin{array}{l}\text { Subordination; } \\
\text { integration }\end{array}$ & $\begin{array}{l}\text { Coordination/parataxis; } \\
\text { parallelism; involvement } \\
\text { look, see } \\
\text { ancestors; } \\
\text { proverbs }\end{array}$ & $\begin{array}{l}\text { Chronology; } \\
\text { timeless past; } \\
\text { involvement }\end{array}$ \\
\hline $\begin{array}{l}\text { Conceptual } \\
\text { Correlates }\end{array}$ & Ideas are persuasive & People are persuasive & $\begin{array}{l}\text { Culture is } \\
\text { persuasive }\end{array}$ \\
\cline { 2 - 4 } & $\begin{array}{l}\text { Institutions make } \\
\text { decisions }\end{array}$ & Individuals make decisions & $\begin{array}{l}\text { History, traditions } \\
\text { make decisions }\end{array}$ \\
\cline { 2 - 5 } Structure is crucial & Words are crucial & Aptness is crucial \\
\hline Culture/geography & $\begin{array}{l}\text { Canonical western } \\
\text { (American) }\end{array}$ & Eastern (Arabs) & \\
\hline
\end{tabular}

Table (2): Linguistic, Conceptual and Cultural Correlates of Persuasive Styles (Johnstone 1989, p.145 \& p.151) 
In spite of the problematic nature of dichotomizing cultural patterns, scholars have continued to use Hofstede's I-CD, Johnstone's Persuasive Styles and Hall's high vs. low context cultures to compare Arab and nonArab societies, as reviewed in the coming section.

\subsection{Arab and American Communicative and Persuasive Styles}

In his autobiography "qiSat 3aql" (Story of a Mind), Mahmoud (1988, p.121) observed that culture has affected Arabs, including Egyptians, to be more inclined to using emotion-arousing language than to reasoningbased one. Such a claim has been the concern of several studies of Arabs' and Westerners' communicative styles (Johnstone 1989; Anderson 1989; Feghali 1987; Nelson 2002; Zaharna 1995; Ghanem \& Speicher 2016).

Feghali maintained that native Arabic speakers, whether communicating in Arabic or other languages, share common features of communicative style, including repetition, indirectness, elaborateness, and affectiveness (1987, pp.357-361). Comparing the rhetorical tactics of Saudi and American advertisers, Anderson (1989) found that different strategies are used for framing arguments. For Americans, the process of thinking is inductive: beginning with facts and proceeding to ideas, using statistics to provide "objective reality" and the world is seen as a unilateral connection of causes and effects, projecting into the future. As for the Saudis, there is emotional tone, use of anti-thesis, or contrasting ideas, parallel structure, rhythm of language, and repetition (1989, p.87). It is maintained that American culture, as low-context, places great emphasis on explicit meaning while Arab cultures, as high context, make greater use of subtle contextual cues in interpreting messages.

Zaharna (1995) contended that the Arab and American cultures have two different perspectives in their view to the role and function of language which would highlight the persuasive preferences of the two cultures. English language being in low-context direct linear literate culture is regarded as an instrument for conveying information, and accurate facts. Language use is expected to be specific, technical and detailed; preference is for clarity, objectivity and directness. Linear and 


\section{Hala Tawfik Sorour Maklad}

literate patterns indicate accuracy, factual presentation of information for documentation purposes and for doing things as well as for argumentative and reasoning purposes (Zaharna, 1995, p.245). For the Arabs, language is "an art form, a religious phenomenon and an identity tool". It does not view language as a means for conveying factual messages and accurate information but rather as a 'social conduit in which emotional resonance is stressed" (pp. 245-246). As described by Hitti (cited in Zaharna, 1995, p.246), the language has the effect of what they call 'lawful magic' ( $\mathrm{siHr}$ Hallal) with the focus on rhyme, rhythm and music, and stress is on style, "eloquence and effectiveness".

However, the findings of Ghanem and Speicher's (2016) quantitative study of persuasive styles and tactics used by Arab and Western debaters in United Nations General Assembly contradicted the claims of the previous literature. For presentational style, it was not indicative of either language group, as the Arabs appeared to incline to use the tactics of emotion, religious references, honorific language and vagueness while westerners used more coordination, syntactic parallelism and repetition. In terms of quasi-logical style, there seems to be several significant differences as the Arabs appeared to use the tactics of cause and effect, universalism, subordination, integration, listing and explicitness more than the westerners who used the statistics tactic more often.

The claims that Arabs prefer emotional-arousing language, presentational and analogical styles while westerners prefer reasoning, and quasi-logical style, have led to "stereotypes of Arab and Western communication patterns and norms of behavior" (10) that have been constantly highlighted in the literature. The study argues that communicative style operates dynamically according to context, and communicators are capable of maneuvering and adapting their styles to serve their purposes.

\subsection{Interculture:}

It has been argued that there is no single language, culture or communicative style, but what we have is "language, culture and communicative style instantiated in several group and individual varieties ... a repertoire of varieties of styles and a combination of styles which are 
deployed according to communicative needs in the changing contexts" (Kecskes, 2015, p.173). In some interactions, the existing styles of communication - the communicative repertoires of speakers - can be modified and blended with "situationally emergent new elements", i.e. a potential process of blending that relies on existing and emerging factors. In this regard, "(B)lending means joining existing and emerging elements/factors into new intercultures". In this sense, culture is a "dynamic phenomenon" where the " $(\mathrm{T})$ he existing relatively definable models are modified and blended with situationally emergent new elements" (Kecskes, 2015, p.174).

Among the crucial factors that manifest interculture are "preferred ways of saying things', expressed in a blend of pre-fabricated language with ad hoc generated language; and preferred ways of organizing thoughts. Another factor is common ground which is the "sum of all the information that people assume they share" that may include world views, shared values, beliefs and situational context (Kecskes, 2015, p. 183). Emergent common ground is the result of creating and co-constructing intercultures in intercultural communication which is built on both actual situational needs and context, as well as existing shared knowledge and information.

\subsection{Statement of the problem:}

Comparative studies of Arab and American communicative and persuasive styles tend persistently to dichotomize cultures: on one hand is the Individualist American culture oriented toward quasi-logical style; on the other hand is the Collectivist Arab culture inclined to presentational and analogical styles. However, with the emergence of hybrid cultural entities such as ENACTUS or AISEC that transcend national homogenous cultures, the study investigates whether the stereotyped style patterns have been replaced by blended

patterns that serve specific purposes in a discursive interculture such as that of ENACTUS. 


\subsection{Questions of the Study:}

Arguing that the discourse of ENACTUS would display a blend of the unmarked existing style(s) and the marked emergent ones to create the ad hoc interculture, the study attempts to answer the following questions:

1. To what extent has ENACTUS as a global youth organization been effective in breaking down cultural stereotypes and building bridges between cultures?

2. How did the values of ENACTUS mediate the influence of national 'Individualist' and 'Collectivist' cultures on the persuasion styles of the teams?

\section{Methodology:}

\subsection{Data:}

The data is extracted from two PowerPoint presentations delivered by teams of University students representing ENACTUS USA and Egypt in the World Cup Competition of 2012 (respectively https://www.youtube.com/watch?v=vao7Crvd2gQ;

https://www.youtube.com/watch?v=ynP8D8sIf7U). The American team represents Belmont University while the Egyptian team represents French University in Egypt. The data analyzed are two synchronized components of the presentation: the verbal spoken utterances, and the visual synchronized slides. The presentations of these two teams in particular are chosen because the American team won the competition while the Egyptian team was placed second, which means that they both managed to convince the judges of their credibility, yet in varying degrees.

In a PowerPoint presentation, a person speaks before an audience using projected PowerPoint texts as visual aids (Yates \& Orlikowski, 2007, p.68). As a digital tool, PowerPoint has made it possible to integrate various signs to create meanings and convey persuasive messages. The PowerPoint presentations delivered by Egyptian and American university students showcased a number of community projects 
before judges. The main purpose of the audio, visual and verbal presentations is to convince the judges that the team did the best job in using an entrepreneurial approach, improving the quality of life and standard of living of their community, as stated in the judging criterion (SIFE Team Handbook, 2012, p. 42). Advised to sell their team (p.68), students deliver soft-sell sales presentations, where subtle persuasion is presumably used. The argumentative PowerPoint presentation of ENACTUS teams belongs to institutional discourse where the interaction and the speakers' goals are partially determined by the institution involved (Freed, 2015), which makes it a potential repository of hybrid verbal and visual communicative and persuasive styles.

\subsection{What is ENACTUS?}

ENACTUS is an international nonprofit organization concerned with motivating university students all over the world to improve their local and global communities through entrepreneurial action, providing them the opportunity to launch and sustain community development projects (www.enactus.org). Students are guided by academic advisers and supported by business leaders to adopt an entrepreneurial approach that aims at empowering people (emphasis mine).

A number of studies have identified relationships between individualism and entrepreneurship characterized by "the willingness of people to violate norms as well as their level of achievement motivation" (Codrina, 2008). The high levels of entrepreneurship within the USA have been attributed to cultural values as freedom, independence, selfsufficiency, individualism, achievement, and materialism (Codrina, 2008). The other concept cherished by ENACTUS is empowerment which is defined as the "management practice of sharing information, rewards, and power with employees" to take initiative, make decisions and solve problems, reflecting the tendency to harmonious interdependence and fostering in-group membership (http://www.businessdictionary.com). Hence, the main values of ENACTUS: empowerment and entrepreneurship are a blend of collectivism and individualism as they tend to develop and nourish the 
independent self through in-group activities and innovative projects.

\subsection{Procedures of Data Analysis:}

The PowerPoint presentation of each team is segmented into two stage: Opening and Evidence. The closing part has been excluded for being a brief verbal and visual repetition of the two stages. The Opening is thoroughly analyzed, while in the second stage, one project only is selected as representative of the Evidence. Each stage is analyzed into verbal utterances and visual slides. Total number of utterances analyzed are 95, and of visual slides 111 distributed as follows:

\begin{tabular}{|l|l|l|l|}
\hline Stages & Egyptian Team & American Team & Total \\
\hline Stage I Opening & 22 & 19 & 41 \\
\hline Stage II Evidence & 29 & 25 & 54 \\
\hline Total & 51 & 44 & 95 \\
\hline
\end{tabular}

Table ( 3 ) Distribution of Verbal Utterances.

\begin{tabular}{|l|l|l|l|}
\hline Stages & Egyptian Team & American Team & Total \\
\hline Stage I Opening & 14 & 37 & 51 \\
\hline Stage II Evidence & 26 & 34 & 60 \\
\hline Total & 40 & 71 & 111 \\
\hline
\end{tabular}

Table ( 4 ) Distribution of Visual Slides

The study draws on (a) Johnstone's model of persuasive styles: Presentational, Quasi-Logical and Analogical (1989); and on (b) Ghanem and Speicher's Persuasive tactics (2016). Yet the researcher added or skipped tactics, based on the data at hand. Further a thorough model of analysis has been developed to identify verbal and visual Persuasive tactics through linguistic and visual grammar markers.

\subsubsection{Verbal Markers of Persuasive Tactics: Model of Analysis}

To identify the semantic, syntactic and pragmatic markers that reveal persuasive tactics, the study refers to Ungerer's Emotional Inferencing Principles (1997), Carter and McCarthy (2006), Biber, Johansson, Leech, Conrad, and Finegan (2007), Hyland's approach to 
Engagement (2005), Cooperative Principle (Grice, 1975) and Speech Act theory (Searle 1979). Three styles are addressed in the light of I-C Dimension: (a) Collectivist Presentational, (b) Collectivist Analogical, and (c) Individualist Quasi-Logical. The tactics and verbal markers of each Style are presented in the following table:

\begin{tabular}{|c|c|c|}
\hline \multicolumn{3}{|c|}{ Collectivist Presentational Style } \\
\hline & Tactics & Markers \\
\hline \multirow[t]{5}{*}{1} & \multirow{5}{*}{$\begin{array}{l}\text { Triggering emotions: } \\
\text { Measured by Emotional } \\
\text { Inferencing Principles and } \\
\text { strategies (Ungerer, 1997, } \\
\text { p.313) }\end{array}$} & $\begin{array}{l}\text { Principle of emotional evaluation: } \\
\text { Attitudinal Stance markers (Biber et al 2007, } \\
\text { pp.974-5); and mental verbs (pp.362-3). }\end{array}$ \\
\hline & & $\begin{array}{l}\text { Principle of intensity of presentation: } \\
\text { rhyme and/or rhythm - sweet talk or lawful } \\
\text { magic - music, repetition, paraphrase, } \\
\text { parallel structure, parataxis, rhetorical } \\
\text { question, metaphor, antithesis, emphatic } \\
\text { headers and tails (Carter and McCarthy, } \\
\text { 2006, pp.192-6); and exclamative clause } \\
\text { (p.543) }\end{array}$ \\
\hline & & $\begin{array}{l}\text { Principle of emotional content: descriptive } \\
\text { emotion terms (Ungerer, 1997, p.314). }\end{array}$ \\
\hline & & $\begin{array}{l}\text { Principle of proximity: deictic items, } \\
\text { personal pronouns, determiners, use of first } \\
\text { names and terms of endearment (Ungerer, } \\
\text { 1997, pp.314-5) }\end{array}$ \\
\hline & & $\begin{array}{l}\text { Principle of animacy (Life or Death } \\
\text { Principle): causative and activity verbs } \\
\text { (Biber et al, 2007, pp. 361-2) related to } \\
\text { improving life quality or causing human } \\
\text { disasters. }\end{array}$ \\
\hline 2 & Vagueness & $\begin{array}{l}\text { Hedges (Biber et al, p.547); approximators } \\
\text { (pp.557-8); symbols and generic reference } \\
\text { (p.265), }\end{array}$ \\
\hline 3 & Indirectness & $\begin{array}{l}\text { Flouting Maxims of Quantity, Quality, } \\
\text { Manner or Relevance (Grice, 1975). }\end{array}$ \\
\hline 4 & $\begin{array}{l}\text { Collectivity: in-group } \\
\text { membership }\end{array}$ & $\begin{array}{l}1^{\text {st }} \text { plural personal and possessive pronouns: } \\
\text { We/Our }\end{array}$ \\
\hline 5 & Involvement & $\begin{array}{l}2^{\text {nd }} \text { person pronoun; Appealing to shared } \\
\text { knowledge (Hyland, 2005). }\end{array}$ \\
\hline \multicolumn{3}{|c|}{ Collectivist Analogical Style } \\
\hline 1 & Storytelling & $\begin{array}{l}\text { Contact Clauses or Asyndeton: clauses } \\
\text { coordinated without conjunctions to create a }\end{array}$ \\
\hline
\end{tabular}




\begin{tabular}{|c|c|c|}
\hline \multicolumn{3}{|c|}{ Hala Tawfik Sorour Maklad } \\
\hline & & $\begin{array}{l}\text { "special effect in narrative texts" (Carter and } \\
\text { McCarthy, 2006, p.556). }\end{array}$ \\
\hline 2 & Proverbs & $\begin{array}{l}\text { Old sayings that show wisdom (Johnstone, } \\
\text { 1989, p.149). }\end{array}$ \\
\hline 3 & Temporal Sequence & $\begin{array}{l}\text { Clauses arranged temporally (Labov, 1972, } \\
\text { p.360) }\end{array}$ \\
\hline \multicolumn{3}{|c|}{ Individualist Quasi-Logical Style } \\
\hline 1 & $\begin{array}{l}\text { Statement of Facts: words } \\
\text { represent truth (Nelson, Al } \\
\text { Batal \& El Bakry, 2002). }\end{array}$ & $\begin{array}{l}\text { Assertive speech act with the force of 'state' } \\
\text { where the words fit the world and the speaker } \\
\text { states a proposition for which s/he has } \\
\text { evidence. (Searle, 1979). }\end{array}$ \\
\hline 2 & Statistics & $\begin{array}{l}\text { Numeral Phrases (Biber et al., 2007, p.109- } \\
\text { 113). }\end{array}$ \\
\hline 3 & Numbering/Listing & $\begin{array}{l}\text { Linking and organizational adjuncts (Carter } \\
\& \text { McCarthy, 2006, p.290). }\end{array}$ \\
\hline 4 & Emphasizing Action & $\begin{array}{l}\text { Activity, Communication and Causative } \\
\text { verbs (Biber et al, 2007, p.361-2). }\end{array}$ \\
\hline 5 & Cause and Effect & Logical connectives \\
\hline 6 & Subordination & Hypotaxis: noun, adverb and relative clauses. \\
\hline 7 & $\begin{array}{l}\text { Integration: "packing } \\
\text { more information into an } \\
\text { idea unit by using a variety } \\
\text { of devices for } \\
\text { incorporating additional } \\
\text { elements into idea units" } \\
\text { (Chafe, 1982, p.39). }\end{array}$ & $\begin{array}{l}\text { Nominalization, non-finite clauses, conjoined } \\
\text { phrases and series of phrases, sequence of } \\
\text { prepositional phrases. }\end{array}$ \\
\hline 8 & Directness/Explicitness: & $\begin{array}{l}\text { Direct Speech acts; Maxims of Cooperative } \\
\text { principle: Quality; Quantity; Manner; } \\
\text { Relevance }\end{array}$ \\
\hline 9 & $\begin{array}{l}\text { Individualism: tendency } \\
\text { to show an independent } \\
\text { self (Hofstede, 2015, p.5). }\end{array}$ & Self-Mention; $1^{\text {st }}$ personal singular pronoun. \\
\hline
\end{tabular}

Table (5): Verbal Markers of Persuasive Tactics

\subsubsection{Visual Markers of Persuasive Tactics: Model of Analysis}

To account for visual slides, the first procedure is to typify them into graphical, scriptural and/or pictorial (Rowley-Jolivet, 2004, p.150). To analyze the visual elements in slides, reference is made to Kress and Leeuwen's visual systems of Representational, Interpersonal and Compositional Meanings (2006). As for relations between visual slides or between text and slide, the Intersemiotic Texture approach of Liu and 
O’Halloran (2009) is referred to.

The following table presents the tactics and visual markers of each Persuasive style:

\begin{tabular}{|c|c|c|}
\hline \multicolumn{3}{|c|}{ ollectivist Presentational Style } \\
\hline & Tactics & Markers \\
\hline \multirow[t]{4}{*}{1} & Triggering emotions & $\begin{array}{l}\text { Principle of emotional evaluation: } \\
\text { Interpersonal Meaning: point of view, } \\
\text { showing power through vertical angle; and } \\
\text { Compositional Meaning through Salience } \\
\text { and Information Value (Kress and van } \\
\text { Leeuwen, 2006, p. 177). }\end{array}$ \\
\hline & & $\begin{array}{l}\text { Principle of intensity of presentation: } \\
\text { Sensory Modality (van Leeuwen, 2005, } \\
\text { p.170; Kress \& van Leeuwen, 2006, pp. } \\
\text { 165-6); visual metaphors; visual rhyming } \\
\text { pattern (Kress \& van Leeuwen, 2006, } \\
\text { p.204); Intersemiotic Parallelism including } \\
\text { Homospatiality and Intersemiotic parallel } \\
\text { structure. (Liu \& O'Halloran, 2009); } \\
\text { emphasis through text condensation or } \\
\text { verbal repetition of phrases; inter-image } \\
\text { antithesis; information condensation and } \\
\text { visual summarization. }\end{array}$ \\
\hline & & $\begin{array}{l}\text { Principle of proximity: Interpersonal } \\
\text { Meaning: social distance and Intimacy } \\
\text { (Kress and van Leeuwen, 2006, p.124) } \\
\text { determined by how close participants in an } \\
\text { image appear resulting in feelings of } \\
\text { intimacy and distance. }\end{array}$ \\
\hline & & $\begin{array}{l}\text { Principle of animacy (Life or Death } \\
\text { Principle): } \text { Representational Meaning: } \\
\text { Narrative and Conceptual Processes (Kress } \\
\text { \& Leeuwen, 2006). }\end{array}$ \\
\hline 2 & Vagueness & $\begin{array}{l}\text { Symbols, icons and indexes (Harrison 50); } \\
\text { Conceptual Symbolic Process; High } \\
\text { Abstract Modality with low saturation and } \\
\text { differentiation (Kress and van Leeuwen } \\
\text { 2006, pp.165-166); }\end{array}$ \\
\hline
\end{tabular}




\begin{tabular}{|l|l|l|}
\hline \multicolumn{2}{|c|}{ Hala Tawfik Sorour Maklad } \\
\hline 3 & Collectivity & $\begin{array}{l}\text { Intersemiotic parallel structure when the } \\
\text { actor in the text is We and in the visual is } \\
\text { the team; Conceptual process. }\end{array}$ \\
\hline 4 & Involvement & $\begin{array}{l}\text { Frontal angle and demand pictures (Kress } \\
\text { and van Leeuwen 2006, p.138); }\end{array}$ \\
\hline \multicolumn{2}{|c|}{ Collectivist Analogical Style } \\
\hline 1 & Temporal Sequence & $\begin{array}{l}\text { Intersemiotic Temporal Relations (Liu } \\
\text { and O'Halloran 2009). }\end{array}$ \\
\hline 1 & Statement of Facts & $\begin{array}{l}\text { Representational meaning: Narrative } \\
\text { processes; and Interpersonal Meaning: } \\
\text { High Modality, including highly saturated } \\
\text { colors, and Naturalistic Modality (van } \\
\text { Leeuwen, 2005 p.168; Kress \& Leeuwen, } \\
\text { 2006, pp. 165-6). }\end{array}$ \\
\hline 2 & Statistics & Numerical slides with figures and graphs. \\
\hline 3 & Emphasizing Action & $\begin{array}{l}\text { Representational meaning: Narrative } \\
\text { Action processes (Kress \& Leeuwen, } \\
\text { 2006, p. 59). }\end{array}$ \\
\hline 4 & Logical connection & $\begin{array}{l}\text { Implication Sequences: Intersemiotic } \\
\text { Additive relations; Intersemiotic } \\
\text { Comparative relations; Intersemiotic } \\
\text { Consequential relations (Liu and } \\
\text { O'Halloran 2009). }\end{array}$ \\
\hline 5 & Directness/Explicitness: & $\begin{array}{l}\text { Oblique angle; far social distance where } \\
\text { whole figure with space around it is } \\
\text { pictured (Kress \& Leeuwen, 2006, p. 125) } \\
\text { 2006, pp. 165-6). }\end{array}$ \\
\hline & Detachment & Indistic Modality (Kress \& Leeuwen, \\
\hline
\end{tabular}

Table 6: Visual Markers of Persuasive Tactics

In the coming section, the researcher presents the persuasive styles presumably adopted by both teams in their verbal utterances and visual slides along with their potential cultural orientations in both stages, based on the abovementioned model of analysis. 
3. Persuasive Styles and Cultural Orientations: Results and Discussion

Having analyzed 95 verbal utterances and 111 visual slides into persuasive tactics and styles, the researcher reached the following results.

\subsection{Presentation of Egyptian Team: Persuasive Styles and Cultural Orientations}

The opening stage is made of the following moves: Attracting Attention + Stating Mission and Objectives + Stating Beliefs + Introducing team and projects. The evidence stage includes these moves: Title + Attracting Attention + Stating Community Problem + Describing Solution + Referring to Impact and Sustainability. (For full transcript, see Appendix A).

\subsubsection{Persuasive Styles in Verbal Utterances:}

As shown in table (7), the Egyptian team used the unmarked Presentational style more frequently in the opening stage; yet when presenting evidence in the second stage, they extensively resorted to the marked Quasi-Logical style. The Analogical style is traced in the evidence stage in a very low frequency.

\begin{tabular}{|l|l|l|}
\hline Style & Opening Stage & Evidence Stage \\
\hline Presentational & $65 \%$ (N 38) & $29.4 \%$ (N25) \\
\hline Quasi-Logical & $35 \%$ (N 21) & $67.1 \%$ (N57) \\
\hline Analogical & $0 \%(\mathrm{~N} \mathrm{0)}$ & $3.5 \%(\mathrm{~N} 3)$ \\
\hline Total & $\mathrm{N} \mathrm{60}$ & $\mathrm{N} 85$ \\
\hline
\end{tabular}

Table (7): Stage-based Variation in Persuasive Styles in Verbal Utterances of Egyptian team

Under Presentational style, the unmarked tactics of Triggering emotion and Vagueness are more used in the opening stage than in the evidence one when presenting the project, while the we-attitude 
represented by the tactic of Collectivity is more demonstrated in the evidence stage when showing their efforts to improve the quality of life in Al Manzala community (table 8).

\begin{tabular}{|l|l|l|}
\hline Presentational Tactics & Opening Stage & Evidence Stage \\
\hline P1 Triggering emotions & $52.6 \%(\mathrm{~N} 20)$ & $56 \%(\mathrm{~N} 14)$ \\
\hline P2 Vagueness & $34.2 \%(\mathrm{~N} \mathrm{13)}$ & $8 \%(\mathrm{~N} 2)$ \\
\hline P4 Collectivity & $10.5 \%(\mathrm{~N} 4)$ & $36 \%(\mathrm{~N} 9)$ \\
\hline P5 Involvement & $2.6(\mathrm{~N} 1)$ & $0 \%(\mathrm{~N} 0)$ \\
\hline Total & $\mathrm{N} 38$ & $\mathrm{~N} 25$ \\
\hline
\end{tabular}

Table (8): Stage-based Variation in Presentational Tactics in Verbal Utterances of Egyptian team

Under the Triggering emotions tactic, the unmarked principle of intensity of presentation has been observed by Egyptian team in both stages employing several linguistic markers. To attract attention, the markers of syntactic parallel structure and alliteration are used in the very first utterance of the presentation, e.g. Improving lives, impacting people, making a difference, followed by an exclamative clause what a splendid motive to live for. Syntactic parallel structure is also detected in the scriptural visual slides in the opening stage to brief the audience on their beliefs and mission: $\{(\mathrm{We}) \mathrm{V}+\mathrm{Adj} .+\mathrm{O}\}$, e.g. Achieve outstanding results. Another marker is repetition where the key words that the Egyptian team used repetitively in all stages are 'empowerment' and 'sound of empowerment'. Emphasis on the concept of the empowerment is further added by the use of header: e.g. The sound of empowerment, an objective we continuously strive to achieve in SIFE UFE; and metaphor where empowerment is figuratively used in 'sound of empowerment'; filter for empowerment, a metaphor used to describe the solution in Al Manzala project, creating cohesion between opening and evidence stages.

The principle of emotional evaluation, i.e. attitudinal stance, is reflected in the Egyptian team's tendency to commend their motives, actions and reactions by using positive evaluative modifiers (adjectives): splendid motive, expanded effect, UFE is proud of the sound of 
empowerment and mental verbs expressing emotional and cognitive state: believe, dream, rejoice.

Concerned with showing how life is generated and disaster is caused, the principle of animacy is realized by causative and activity verbs. Stating their mission and goals, Egyptian team used causative and activity verbs referring to change and improvement of people's quality of life: Trigger change, empower, help. When presenting their project, they referred to the disaster faced by Manzalian fishermen - losing their business - then showed how their project revived the business of the people in the area of Al Manzala lake, highlighting the economic and environmental impact of their project.

The Egyptian team lacked precision when using (a) generic reference in the opening stage: impacting people... without stating explicitly who those people are; (b) 'dummy it': It all starts with a small decision; and (c) hedges: Someday somehow everyone will hear the sound of empowerment; and by violating the maxim of manner: dream to be Egypt's change agent, where meaning is in context not in the explicit message. In the evidence stage, lack of precision is marked by generic reference when referring for the first time to the projects they implemented, using a noun phrase that does not refer to a specific entity or process: Aqua-farming: Filter by Nature. Though reflecting the highcontext culture (Hall), Vagueness may have been intentionally and strategically used by the Egyptian team to arouse the interest of the audience and get them involved.

Slightly displaying in-group membership, the Egyptian team used the plural $1^{\text {st }}$ person subject pronoun to refer to their beliefs and actions as one entity: we continuously strive to achieve in SIFE UFE... We always believe that empowerment is not just about...

The team started to get the judges involved at the end of the opening stage by using $2^{\text {nd }}$ person subject pronoun (you), and referring to shared knowledge: As you can see in our annual report all the five 


\section{Hala Tawfik Sorour Maklad}

projects we will be presenting today completely fulfilled the five criteria; we are excited to share our projects with you today.

As for Quasi-Logical style, the preferred tactic in the opening stage is 'Emphasizing action', while the tactics of Facts, Statistics, Emphasizing Action, Integration and Listing are extensively demonstrated in the second stage (table 9).

\begin{tabular}{|l|l|l|}
\hline Quasi-Logical Tactics & Opening Stage & Evidence Stage \\
\hline Q1 Facts & $9.1 \%(\mathrm{~N} 2)$ & $26.3 \%(\mathrm{~N} 15)$ \\
\hline Q2 Statistics & $4.5 \%(\mathrm{~N} 1)$ & $21 \%(\mathrm{~N} 12)$ \\
\hline Q3 Listing & $0 \%(\mathrm{~N} 0)$ & $10.5 \%(\mathrm{~N} 6)$ \\
\hline Q4 Emphasizing Action & $54.5 \%(\mathrm{~N} 12)$ & $14 \%(\mathrm{~N} 8)$ \\
\hline Q5 Cause \& effect & $4.5 \%(\mathrm{~N} 1)$ & $1.7 \%(\mathrm{~N} 1)$ \\
\hline Q6 Subordination & $13.6 \%(\mathrm{~N} \mathrm{3)}$ & $1.7 \%(\mathrm{~N} 1)$ \\
\hline Q7 integration & $9.1 \%(\mathrm{~N})$ & $14 \%(\mathrm{~N} 8)$ \\
\hline Q8 Directness & $0 \%(\mathrm{~N} 0)$ & $10.5 \%(\mathrm{~N} 6)$ \\
\hline Total & 21 & $\mathrm{~N} 57$ \\
\hline
\end{tabular}

Table (9): Stage-based Variation in Quasi-Logical Tactics in Verbal Utterances of Egyptian team

In the opening stage the tactic of Emphasizing action is significantly expressed by communicative verbs: communicate with target community; pledge improvement, deliver knowledge. Moving to the evidence stage, we find a cluster of Quasi-Logical tactics. Describing the place where the problems occurred, five Quasi-Logical tactics, namely Facts, Integration, Statistics, Subordination and Emphasizing Action, are used in a single utterance: Al Manzala Lake is the biggest natural lake in Egypt producing sixty four thousand tons of fish annually that is sufficient to feed more than eighty thousand persons for a whole year.

Referring to the objectives of their actions, the utterances were direct, logically organized, focusing on specific actions, and integrating several ideas, employing the tactics of Directness, Listing, Cause and 
Effect, Emphasizing Action and Integration: It was time to take action, bring back the value of Manzala so we launched the aqua farming projects with two main objectives; to adapt new aqua farming solutions and to revive the business. The actions taken to solve the problem of $\mathrm{Al}$ Manzala fishermen are presented as Facts, realized by Assertive Speech Act, along with Statistics (numeral phrases), Emphasizing action (activity verbs) and Integration (non-finite clauses): our first action was to collaborate with a renowned expert in the aqua farming field to make fifty farmers aware of the advantages of carp fish.

The results of their efforts are also expressed through Facts, Statistics, and Integration, making prediction about the future based on the present situation: in one year, the aqua farmers shared 110 tons of carp worth one hundred and thirty three US dollars; the Aqua farmers net profit will generate four thousand and sixty USD allowing him to save two hundred and eighty USD monthly and exceeding the Egyptian minimum wage by forty percent.

The Egyptian team employed the Analogical style with very low frequency in the evidence stage. They started telling the problem of Al Manzala Lake by quoting a Chinese proverb that originally reads: Give $a$ man a fish, and you feed him for a day. Teach a man to fish, and you feed him for a lifetime. This proverbs calls for alleviating poverty by facilitating self-sufficiency, but it is modified in the presentation to read: Give a man a fish and he will eat for a day, but teach him how to fish in Al Manzala Lake and he will lose his business the very next day, stating an unexpected result that attracts attention to the problem and triggers feelings of surprise and sympathy.

\subsubsection{Visual Slides:}

Slides serve as supportive moves for the verbal utterances and in many cases are inter-semiotically related. In the opening stage, the components of slides are mainly abstract graphics along with verbal phrases synchronized with live music; in the evidence stage, most of the 


\section{Hala Tawfik Sorour Maklad}

\begin{tabular}{lllll}
\hline slides & are & Scriptural/Graphical, followed
\end{tabular}

Pictorial/Scriptural/Graphical, providing visual summarization and semantic condensation, to complement the facts and statistics presented in the spoken utterances (table 10).

\begin{tabular}{|l|l|l|}
\hline Type of Slide & Opening Stage & Evidence Stage \\
\hline Scriptural & $7.1 \%(\mathrm{~N} 1)$ & \\
\hline Graphical & 0 & $7.7 \%(\mathrm{~N} 2)$ \\
\hline Scriptural/Graphical & $92.9 \%(\mathrm{~N} 13)$ & $34.6 \%(\mathrm{~N} 9)$ \\
\hline Pictorial/Scriptural/Graphical & 0 & $26.9 \%(\mathrm{~N} 7)$ \\
\hline Graphical/Scriptural/Numerical & 0 & $23.1 \%(\mathrm{~N} 6)$ \\
\hline Graphical/Numerical & 0 & $7.7 \%(\mathrm{~N} 2)$ \\
\hline Total & $\mathrm{N} 14$ & $\mathrm{~N} 26$ \\
\hline
\end{tabular}

Table (10): Stage-based Variation in Slides Type of Egyptian team

Broadly speaking, the Egyptian team's stereotyped tendency to presentational style is evidently demonstrated in the visual slides used in both stages as indicated in table (11).

\begin{tabular}{|l|l|l|}
\hline Style & Opening Stage & Evidence Stage II \\
\hline Presentational & $96.2 \%(\mathrm{~N} 25)$ & $82.9 \%(\mathrm{~N} 29)$ \\
\hline Quasi-Logical & $3.8 \%(\mathrm{~N} 1)$ & $17.1 \%(\mathrm{~N} 6)$ \\
\hline Total & N26 & N35 \\
\hline
\end{tabular}

Table (11): Stage-Based Variation in Persuasive Styles in Visual Slides of Egyptian team

Specifically, two Presentational tactics are detected, mainly Vagueness indicating the high context culture, and Triggering Emotions, the unmarked tactic of Arab persuasive style (table 12).

\begin{tabular}{|l|l|l|}
\hline Presentational Tactics & Opening Stage & Evidence Stage \\
\hline P1 Triggering emotions & $48 \%(\mathrm{~N} 12)$ & $41.4 \%(\mathrm{~N} 12)$ \\
\hline P2 Vagueness & $52 \%(\mathrm{~N} 13)$ & $48.3 \%(\mathrm{~N} 14)$ \\
\hline P3 Involvement & 0 & $10.3 \%(\mathrm{~N} 3)$ \\
\hline Total & $\mathrm{N} 25$ & $\mathrm{~N} 29$ \\
\hline
\end{tabular}

Table (12): Stage-Based Variation in Presentational Tactics in Visual Slides of Egyptian team 
To arouse the emotions of the audience at the very beginning of the presentation, the visual components of Egyptian team's slides are colors, graphics and words (verbal phrases) which contributed to marking the principles of intensity of presentation and evaluation. The emotion targeted by the Egyptian team is to impress and gain the attention and admiration of the audience. The phrases along with the colors and graphs created intersemiotic parallel structure, forming one process configuration. As shown in figure (1) we see a slide with green colour in background, dancing dotted line - a conceptual symbolic process, and a phrase with a narrative action process: rejoice in people's achievement, indicating that the team - the Actor - and the projects, symbolically represented by the dotted line, dance joyfully in circumstances coloured in green that represents fertility and vegetation in Egyptian culture (De Bortoli \& Maroto, NA). Other markers include (a) intersemiotic homospatiality (figure 2), where the letter $O$ of the words sound and empowerment are shaded representing the ball that has been moving in all slides; and (b) visual audio metaphor where the violinist stands for the producer of the sound of empowerment.

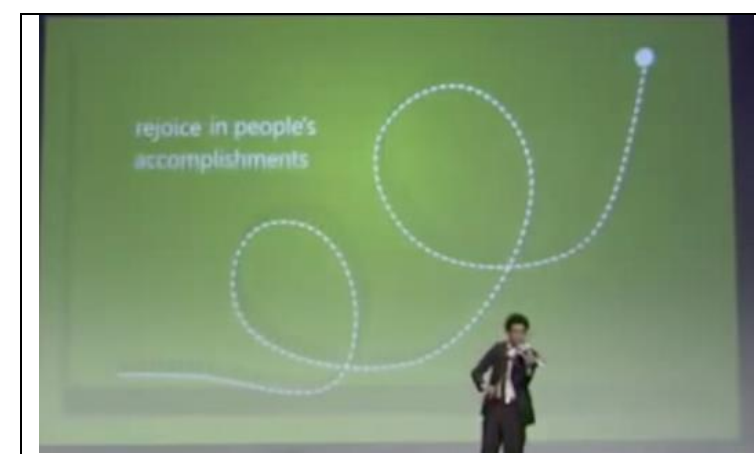

Fig. (1)

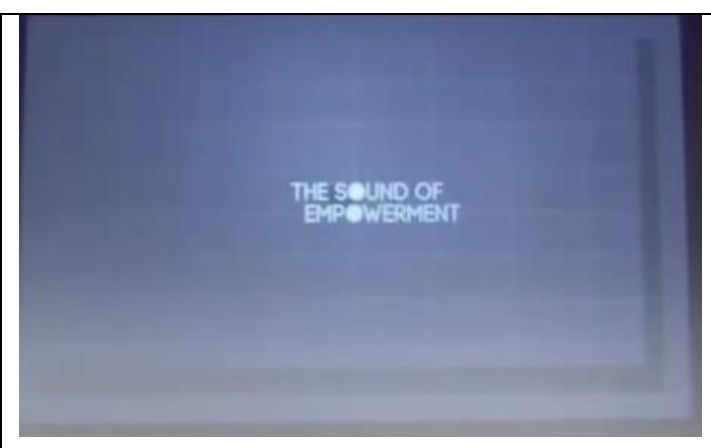

Fig (2)

For emotional impact while visually presenting the evidence stage, Egyptian team tends to exploit the principles of intensity of presentation, evaluation, animacy and proximity. The emotion targeted is getting the audience's admiration for the solution they reached to solve the problem of $\mathrm{Al}$ Manzala aqua farmers. Condensation of information and intersemiotic parallel structure are the unmarked devices. In the slides shown below, for example, a cohesive tie is created between the verbal utterance "In one year, the aqua farmers shared 110 tons of carp worth 


\section{Hala Tawfik Sorour Maklad}

133,000 US dollars" and the visual slide by presenting one narrative/action process configuration. By visually summarizing the results achieved in one year, including production and revenues, the slide boosts the principle of animacy since it shows the success of the team in reviving the fishermen's business.

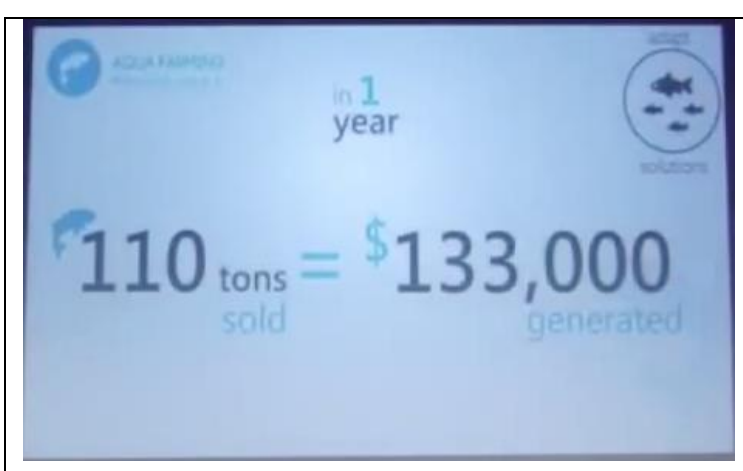

Fig. (3)

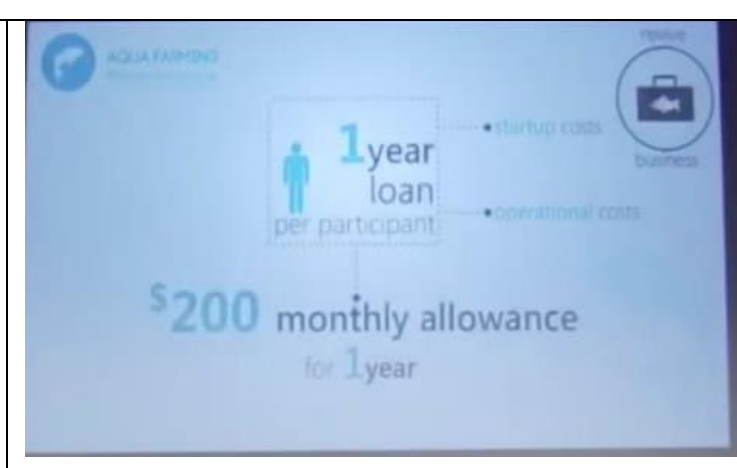

Fig (4)

As for the principle of evaluation, it is observed in the Egyptian team presentation in both stages by Information Value and Salience. The Egyptian team presents what is important for them by placing it at the upper part of the slide, the Ideal - what the team aspires - and at lower part, the Real - What they actually achieved. In the center stands their key concept Sound of Empowerment with capitalized letters to emphasize its salience. In the above slide (Fig. 3), the Ideal - the aqua farming project - is at the top and at the bottom are the real - the number of sold tons of fish and profits generated in dollars, given salience through large fonts. In Figure 4, we see the project title and symbol at the top left, and the aspired objective "revive business" at the top right which represents the Ideal, below which is the customized financial plan " 1 year loan per participant" along with $\$ 200$ monthly allowance in rather larger fonts, representing the real, or what has been actually provided by the team.

In the opening stage, the slides show vagueness signified by High Abstract Modality, with low saturation using grey and blue colors, low contextualization and differentiation along with the use of symbols which have no connection to any particular object or person. Presenting their projects visually, the Egyptian team's first slide is a vague graphical one 
with low saturated monochrome grey; In the middle is an extended line with five balls representing the five projects they are going to present (Fig. 5).

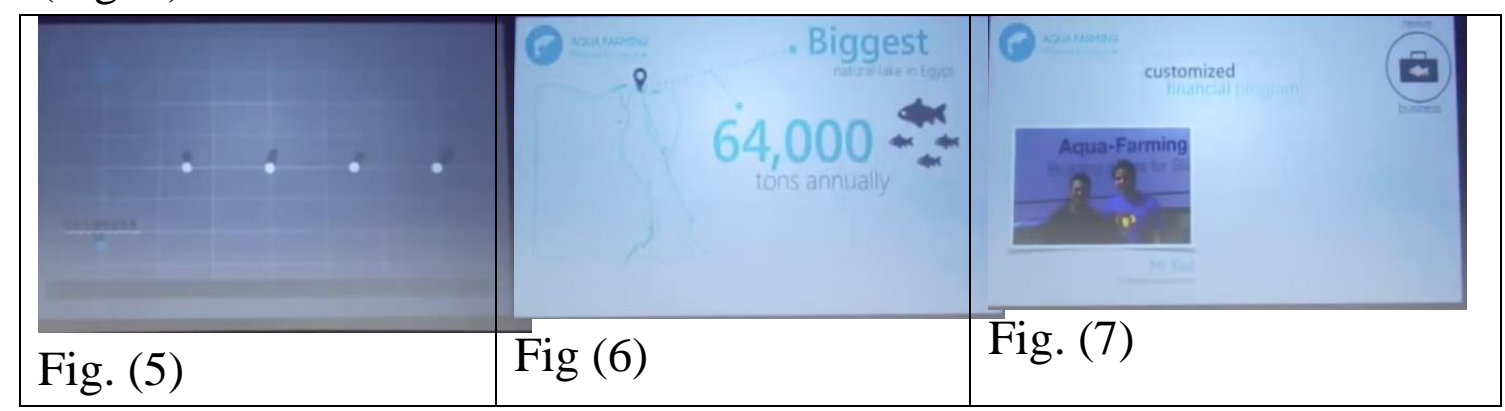

This tactic of Vagueness or lack of visual precision prevails in the presentation of the project, realized by high Abstract Modality, and marked by low saturated blue and use of symbols and icons (Fig.6).

In the pictorial part of the slides (Fig.7), the tactic of Involvement is slightly observed through the use of Frontal angle and Demand picture where the participants, the beneficiary aqua farmers, are looking directly at the viewer, placed at the bottom of the slide to represent what is real.

As for Quasi-Logical style (table 12), it is noted that Logical Connection is the only tactic detected in the slides of the opening stage, marked by Intersemiotic Consequential relations between music and verbal utterance. While the music is played live, the presenter says: someday everyone will hear the sound of empowerment, implying that "because of the music composed and played by the violinist, everyone will hear the sound of empowerment".

\begin{tabular}{|l|l|l|}
\hline Quasi-Logical Tactics & Opening Stage & Evidence Stage \\
\hline Logical Connection & $100 \%(\mathrm{~N} 1)$ & 0 \\
\hline Statistics & 0 & $100 \%(\mathrm{~N} 6)$ \\
\hline Total & $\mathrm{N} 1$ & $\mathrm{~N} 6$ \\
\hline
\end{tabular}

Table (12): Stage-based Variation in Quasi-Logical Tactics in Visual Slides of Egyptian team 


\section{Hala Tawfik Sorour Maklad}

In the evidence stage, Statistics is the only Quasi-Logical tactic in Numerical slides, displayed in large fonts.

To visually support their data and evidence presented verbally in each move, the Egyptian team used Statistics tactic realized by numeral phrases written in large fonts. This tactic further enforces the degree of abstraction featured in the visual presentation of the Egyptian team.

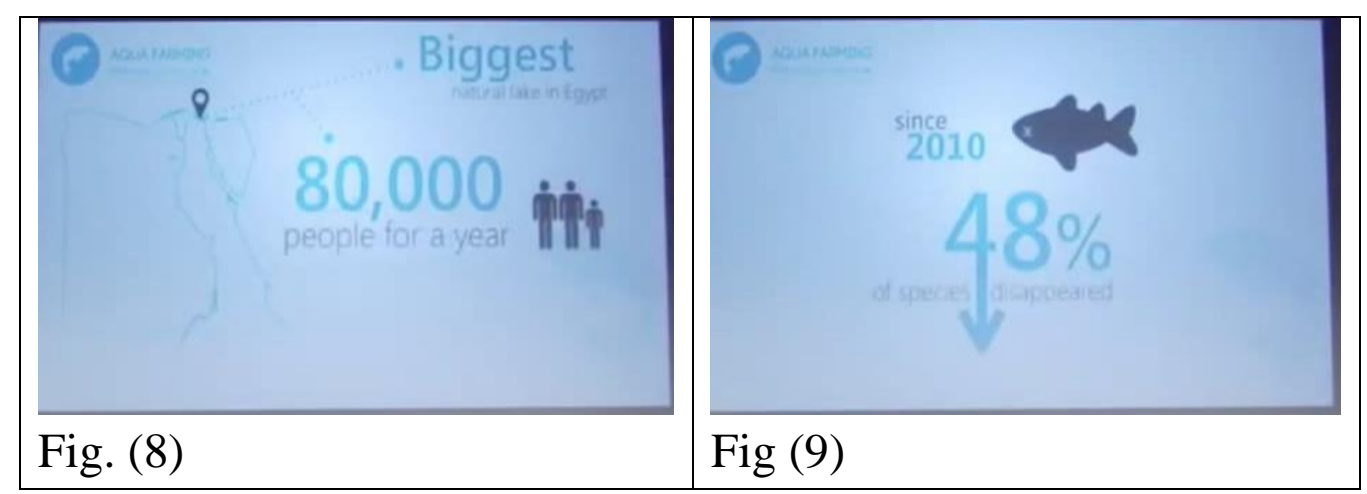

As shown in the above figures, numeral phrases are intertwined with symbols and icons with low saturated high abstract modality

\subsubsection{Cultural Orientations:}

The Egyptian team's presentation tends to reflect an ad hoc interculture created by merging existing unmarked patterns of communication with new marked ones for persuading the judges especially in the verbal component of their presentation. Aware of the purpose of each stage, presenters strategically maneuvered and blended persuasive tactics whenever necessary. In the opening stage, the Egyptian team's presentation projected unmarked collectivist pattern with reliance on emotional resonance, symbols, high degree of abstraction, lack of precision, and most importantly intuitive reasoning. Focusing verbally and visually on repeating the value of empowerment, the Egyptian team did not provide a concrete evidence but rather an abstract one, demonstrated by the extensive use of graphical and scriptural slides, characterized by high abstract modality and low contextualization.

However, the individualist cultural orientation has become verbally evident in the evidence stage, which reflects a shift in their strategic 
maneuver to persuade the judges. In most parts of the evidence stage, the marked Individualist Quasi-Logical tactics are used, presenting facts and statistics, emphasizing actions, stating causes of the problem and effects of their solution, and listing the stages of their customized financial system. By the end, they resorted to the unmarked Presentational tactics to accentuate how their project empowered aquafarmers in Al Manzala lake. While the verbal message has been clear and explicit, based on facts and statistics, the visual one has remained vague and abstract, based on symbols and words, basically characterized by intuitive reasoning. It is left to the audience to infer meaning from what they listen to and see without presenting any concrete evidence. Interestingly, the value of Collectivity has not been highlighted verbally or visually. Such a blend of tactics and styles tend to place the Egyptian team not on the extreme end of collectivism but rather close to the middle, refuting largely the claims of cultural stereotypes and dichotomy.

\subsection{Presentation of American Team: Persuasive Styles and Cultural Orientations}

The moves of the opening stage include: Attracting Attention + Stating Motivation + Introducing Team and Projects + Stating Mission and Goals. The evidence stage is made of the following moves: Title + Stating Community Problem + Stating Background of Solution + Stating Actions Taken + Referring to Impact and Sustainability (For full transcript, see Appendix B).

\subsubsection{Verbal Utterances:}

As shown in table 13, the preferred style of American team in both stages is the Qausi-Logical, which is more frequently employed than the Presentational one, while the Analogical is used only in the evidence stage.

\begin{tabular}{|l|l|l|}
\hline Style & Opening Stage & Evidence Stage \\
\hline Presentational & $44.7 \%(\mathrm{~N} 34)$ & $38.9 \%(\mathrm{~N} 35)$ \\
\hline Quasi-Logical & $55.3 \%(\mathrm{~N} 42)$ & $51.1 \%(\mathrm{~N} 46)$ \\
\hline
\end{tabular}




\section{Hala Tawfik Sorour Maklad}

\begin{tabular}{|l|l|l|}
\hline Style & Opening Stage & Evidence Stage \\
\hline Analogical & 0 & $10 \%$ (N9) \\
\hline Total & N 76 & N 90 \\
\hline
\end{tabular}

Table 13: stage-based variation in Persuasive Styles

It is found that the American team tends to trigger emotions in the evidence stage more than in opening one, while their tendency to show in-group membership is more elaborate in the opening stage than in the presentation of projects, i.e. evidence stage (Table 14).

\begin{tabular}{|l|l|l|}
\hline Presentational Tactics & Opening Stage & Evidence Stage \\
\hline Triggering emotions & $47.1 \%(\mathrm{~N} 16)$ & $60 \%$ (N 21) \\
\hline Vagueness & $0 \%(\mathrm{~N} 0)$ & $5.7 \%$ (N2) \\
\hline Collectivity & $47.1 \%(\mathrm{~N} 16)$ & $31.4 \%$ (N11) \\
\hline Involvement & $5.8(\mathrm{~N} 2)$ & $2.9 \%(\mathrm{~N} 1)$ \\
\hline Total & $\mathrm{N} 34$ & $\mathrm{~N} 35$ \\
\hline
\end{tabular}

Table 14 Stage-based variation in Presentational tactics in Verbal Utterances of American team

To attract attention in the opening stage, the principle of intensity of presentation has been observed at the very beginning through several stylistic markers that include (a) header, e.g. From coast to coast nature's beauty surrounds our people; (b) rhyme, e.g. from our hidden caves to ocean waves (c) anti-thesis and (d) religious reference.

Notably, antithesis is achieved at two levels: small scale and large scale. At the small scale, prepositional phrases are para-tactically connected contrasting natural scenery: From the syenite of the death valley to the snowcapped peaks of Mount McKinley...;From the plunging depth of Grand Canyon to the rising geysers of Yellowstone. On a large scale, clauses are para-tactically joined by the antithetical agent 'but' contrasting the beauty of nature with the trash in the landfills: We've been blessed with incredibly rich and diverse resources. But all of this beauty is not what we see each day...Instead we see usable material being thoughtlessly discarded in landfills slowly destroying our environment. The tactic of Religious Reference is realized by the verb 
bless as God only can endow such resources; and giving the title "Be a Blessing" to their project.

Other markers include syntactic parallel structure and repetition used to highlight problems in their community e.g. we see usable material being thoughtlessly discarded; we see people discarding their lives; and to draw attention to their efforts in evidence stage: We helped Bollie set up a bank account... We explained basic inventory strategies to market and display the bracelet. Several metaphors are used, describing the projects as the lifeblood of our members, comparing the students to soldiers serving on the frontlines, and regarding the projects as a game where empowerment is figuratively compared to a handing off point.

The American team also expressed their emotional stance towards the target communities using mental emotional verbs and negative evaluative modifiers: our team has been moved by those discarded throughout our local and global communities; and the causes and manner of environment destruction: material thoughtlessly discarded in landfills slowly destroying our environment. By expressing their concern, the American team inclines to the other-orientation or Collectivism. In the meantime the sense of ownership is highly appreciated: e.g. to give them the sense of ownership and pride in supporting their home, to signify both empowerment and entrepreneurship.

Concerned with showing how life is generated and disaster is caused, American team strategically exploited the principle of animacy through: (a) stating their mission and goals, using causative and activity verbs related to improving people's quality of life: enable and empower the non-profit to self-manage a sustainable profitable social enterprise; and (b) presenting their evidence, describing the ordeal faced by the Guatemalan orphans along with the disastrous outcomes. The American presenters' lexical choices conveyed explicit negative overtones further boosted by alliteration: "girls who have been abandoned, abused or become pregnant as victims of incest". The same principle is exploited again to refer to life generating ideas when explaining how the team 


\section{Hala Tawfik Sorour Maklad}

ended this plight through their social enterprise, employing a chain of causative verbs, we helped her grow and develop her social enterprise.

Collectivity is frequently demonstrated by American team, displaying tendency to in-group membership. The American team has extensively used the plural $1^{\text {st }}$ person subject, possessive and accusative pronouns to highlight the value of Collectivity: we will be using a three stage system to describe our projects; and to refer to the actions they performed or the plans they made.

American presenters attempted to get the judges involved at the end of the opening stage by using $2^{\text {nd }}$ person subject pronoun (you), and referring to shared knowledge we are excited to share our projects with you today; and in the evidence stage when the presenter pointed to the pictorial slides, saying These are some of her Guatemalan contexts" using Exophora in an attempt to get the audience involved.

As shown in table 15, the most preferred Quasi-Logical tactic in both stages is Emphasizing action, realized by activity verbs: our stage two projects build on these relationships that we foster with community partners to move them towards self-sufficiency, which fits with the Activity orientation where doing not saying is the dominant feature.

\begin{tabular}{|l|l|l|}
\hline Quasi-Logical Tactics & Opening Stage & Evidence Stage \\
\hline Facts & $7.1 \%(\mathrm{~N} 3)$ & $13 \%(\mathrm{~N} 6)$ \\
\hline Statistics & $4.8 \%(\mathrm{~N} 2)$ & $6.5 \%(\mathrm{~N} 3)$ \\
\hline Listing & $7.1 \%(\mathrm{~N} 3)$ & $6.5 \%(\mathrm{~N} 3)$ \\
\hline Emphasizing Action & $35.7 \%(\mathrm{~N} 15)$ & $23.9 \%(\mathrm{~N} 11)$ \\
\hline Cause \& effect & $4.8 \%(\mathrm{~N} 2)$ & $6.5 \%(\mathrm{~N} 3)$ \\
\hline Subordination & $9.5 \%(\mathrm{~N} 4)$ & $10.8 \%(\mathrm{~N} 5)$ \\
\hline Integration & $11.9 \%(\mathrm{~N} 5)$ & $19.6 \%(\mathrm{~N} 9)$ \\
\hline Directness & $9.5 \%(\mathrm{~N} 4)$ & $8.9 \%(\mathrm{~N} 4)$ \\
\hline Individualism & $9.5 \%(\mathrm{~N} 4)$ & $4.3 \%(\mathrm{~N} 2)$ \\
\hline Total & $\mathrm{N} 42$ & $\mathrm{~N} 46$ \\
\hline
\end{tabular}

Table 15: Stage-based variation in Quai-Logical tactics in verbal utterances of American team 
After introducing the project using the tactic of Listing: our second project is ....it is a stage two project, they stated the causes and effects of the calamity faced by the Guatemalan female orphans, integrating several ideas in a single utterance: In 2009, Guatemala barred all international adoptions. Unfortunately, this policy had two negative outcomes: an increasing number of children remaining in orphanages and a loss of income for so many homes... To help in solving this problem, the American team cooperated with a Guatemalan student to launch an enterprise based on making and selling bracelets. On stating the steps they took, the American team used the tactics of (a) Emphasizing action, e.g. we worked with Bollie; and (b) Integration, e.g. Instead of us giving the orphanage money, we decided....; Understanding that Bollie had already taken a large task, we volunteered to help sell the bracelets. Finally, they presented the outcome of their project through the tactics of Facts and Statistics: over a four thousand dollars were raised to support the orphanage; Those funds alone fully financed the hundred and five girls for approximately three months.

Notably the tactic of Individualism is observed in the American team's presentation, reflected in their choice of lexical items that denotes independence and autonomy: "entrepreneurial spirit... power of enterprise". While trying throughout the opening stage to focus on triggering emotions and enhancing their collective orientation, the American team inclined eventually towards asserting autonomy and selfindependence reflected in lexical choice: self-sufficiency, on their own, self-manage, enterprise.

Story telling is the only analogical tactic used by American team with relatively high frequency to narrate the story of Bollie and the orphans and how the US team members helped her establish a business on solid professional basis. To keep the chronological order, they used temporal sequence tactic: When we started working with Bollie, she was making bracelets on her own...;Now with supplies coming from Bollie, these daily crafts would be sold with the profits... 


\section{Hala Tawfik Sorour Maklad}

\subsubsection{Visual Slides:}

As shown in table 16, slight variation in slides types is shown at the stages level as Pictorial slides dominate, followed by Pictorial/Scriptural where the picture is the dominant element and a caption is a subsidiary one. The slides are rich with visual information complemented with verbal spoken utterances. As stated by Kjeldsen (2013), pictures can offer a "rhetorical enthymematic process" and "rational condensation" which makes them the "visual counterpart of verbal argumentation" (3), in addition to their potential "to provide vivid presence (evidentia), realism and immediacy in perception", which cannot be achieved with words only (p.4).

\begin{tabular}{|l|l|l|}
\hline Type of Slide & Opening Stage & Evidence Stage \\
\hline Scriptural & 0 & $20.6 \%(\mathrm{~N} 7)$ \\
\hline Pictorial & $45.9 \%(\mathrm{~N} 17)$ & $58.8 \%(\mathrm{~N} 20)$ \\
\hline Pictorial/Scriptural & $45.9 \%(\mathrm{~N} 17)$ & $20.6 \%(\mathrm{~N} 7)$ \\
\hline Graphical/Scriptural & $8.2 \%(\mathrm{~N} 3)$ & 0 \\
\hline Total & $\mathrm{N} 37$ & $\mathrm{~N} 34$ \\
\hline
\end{tabular}

Table 16: Stage based variation in Types of Slides

Similar to verbal utterances, the Quasi-Logical style is the preferred one in both stages (table 17).

\begin{tabular}{|l|l|c|}
\hline Style & Opening Stage & Evidence Stage \\
\hline Presentational & $46 \%(\mathrm{~N} 29)$ & $32.7 \%(\mathrm{~N} 18)$ \\
\hline Quasi-Logical & $54 \%(\mathrm{~N} 34)$ & $67.3 \%(\mathrm{~N} 37)$ \\
\hline Total & N63 & N55 \\
\hline
\end{tabular}

Table 17: Stage based variation in Persuasive style in visual slides of American team

As shown in table (18), in the opening stage, the most frequently used tactic is Explicitness, and Matter of Fact in the evidence stage; while Logical Connection is a common factor in both stages. 


\begin{tabular}{|l|l|l|}
\hline Quasi-Logical Tactics & Opening Stage & Evidence Stage \\
\hline Matter of Fact & 0 & $40.5 \%(\mathrm{~N} 15)$ \\
\hline Emphasizing Action & $11.8 \%(\mathrm{~N} 4)$ & $8.2 \%(\mathrm{~N} 3)$ \\
\hline Logical Connection & $32.3 \%(\mathrm{~N} 11)$ & $40.5 \%(\mathrm{~N} 15)$ \\
\hline Explicitness & $38.2 \%(\mathrm{~N} 13)$ & 0 \\
\hline Detachment & $18.7 \%(\mathrm{~N} 6)$ & $10.8 \%(\mathrm{~N} 4)$ \\
\hline Total & $\mathrm{N} 34$ & $\mathrm{~N} 37$ \\
\hline
\end{tabular}

Table 18 stage based variation in Quasi-Logical Tactics in visual slides of American team

Explicitness is realized by the use of strongly saturated colors and highly contextualized Naturalistic Modality. Further, the choice of Red colour (Fig. 10), directly associated with danger, is a feature of High Sensory Modality in slides that show disaster. This is associated with several variants of Logical Connection tactic where Intersemiotic Comparative relation is shown by using the picture to specify what is stated in the verbal text. For example, the pictures of mountains, valleys, geysers and lakes specify the kind of beauty that surrounds people as shown in figures 11 and 12. Another Inter-semiotic relation is Consequence where the verbal utterance is the reason behind the action process displayed in figure 10: because our team has been moved, we take care of them and carry the weak ones.

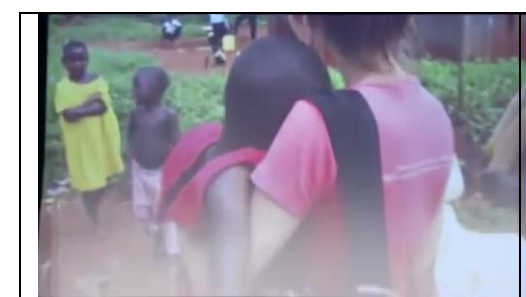

Fig. (10)

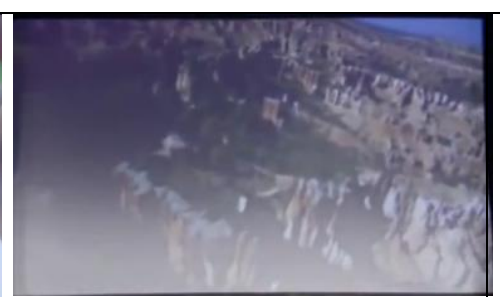

Fig (11)

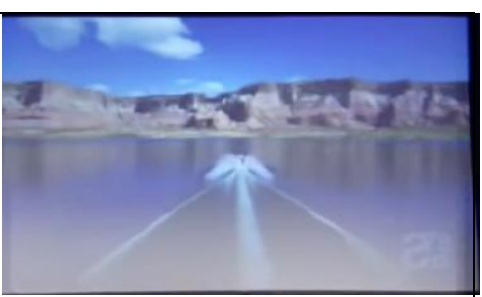

Fig. (12)

Logical Connection prevails also in the evidence stage, realized by Intersemiotic Comparative relations, where the verbal utterances specify the visual slides: "We introduced Bollie to an all-female orphanage in desperate need of funding, The Mary and Martha Orphanage" (synchronized with Fig. 13), and "We worked with Bollie to develop our relationship with the nuns of the orphanage" (Fig. 14). 


\section{Hala Tawfik Sorour Maklad}

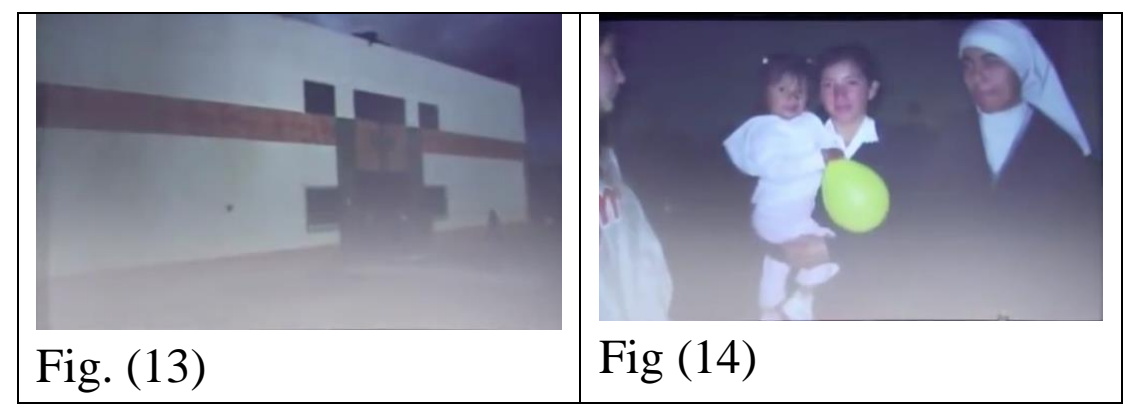

Another significant Logical Connection is between Slides where an Intersemiotic Consequential Relation is detected. The first slide, the decision of closing the Adoption program (Fig. 15) is the cause of the Demand picture of the female orphans in the second slide (Fig. 16).

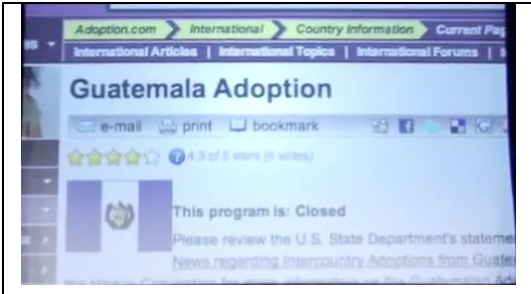

Fig. (15)

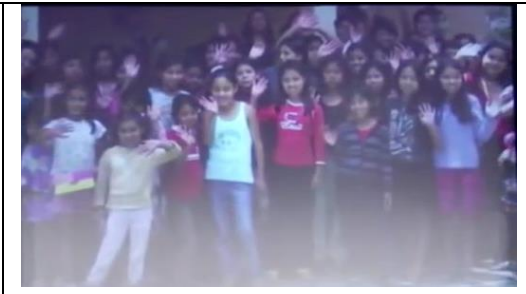

Fig. (16)

Briefing the audience on their projects the American team resorts to Emphasizing Action tactic through displaying actors and action processes in their pictorial slides showing the action processes of teaching, guiding, and dismantling mattresses performed by teachers, mentors and workers, as shown in figures 17 and 18.

\begin{tabular}{|l|l|l|}
\hline & $\begin{array}{c}\text { 3Stage } \\
\text { Process } \\
\text { Teaching }\end{array}$ \\
\hline Fig. (17) & Fig (18) \\
\hline
\end{tabular}

In the evidence stage, action is emphasized visually by narrative action processes and the actors, the working girls, are depicted as totally absorbed in making bracelets, as shown in figures 19 and 20. 


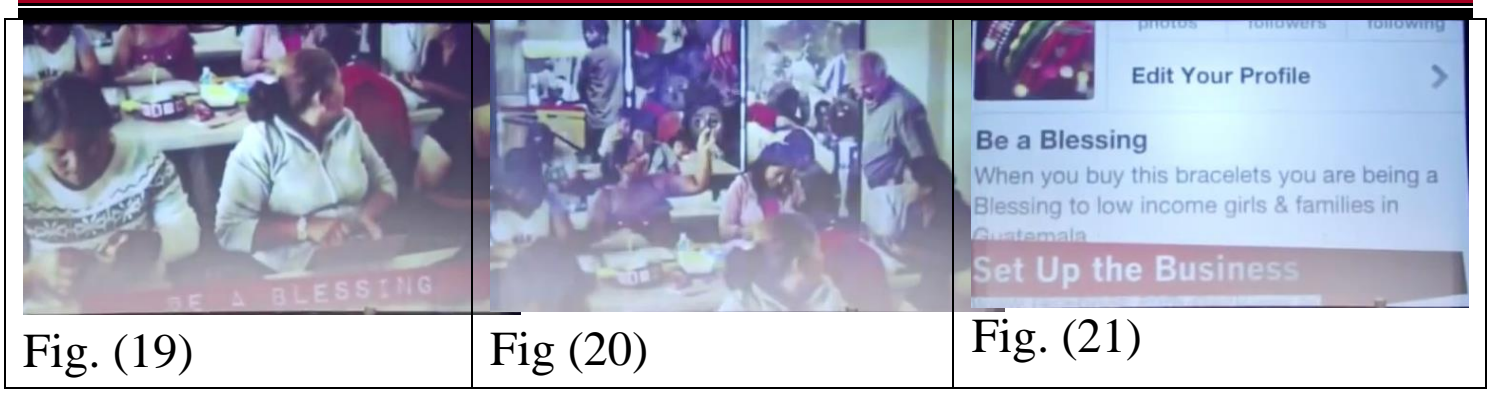

In every move of the evidence stage, the pictorial and pictorial/scriptural slides of the American team act as visual vivid verifier for the verbally performed Assertive Speech Act. They tend to document the causes and facets of the Guatemalan girls' plight and then the actions taken by the team to empower and help establish the free enterprise. This is realized by highly saturated and contextualized Naturalistic Modality, bringing evidence from real life situations (fig. 20) or website (fig. 21).

As for presentational tactics, American team tends to show slides that trigger emotions more frequently in the opening stage than in the evidence one (Table 19).

\begin{tabular}{|l|l|l|}
\hline Presentational Tactics & Opening Stage & Evidence Stage \\
\hline P1 Triggering emotions & $55.1 \%(\mathrm{~N} 16)$ & $38.9 \%(\mathrm{~N} 7)$ \\
\hline P2 Vagueness & $17.2 \%(\mathrm{~N} 5)$ & $38.9 \%(\mathrm{~N} 7)$ \\
\hline P3 Involvement & $24.1 \%(\mathrm{~N} 7)$ & $16.7 \%(\mathrm{~N} 3)$ \\
\hline P4 Collectivity & $3.4 \%(\mathrm{~N} 1)$ & $5.6 \%(\mathrm{~N} 1)$ \\
\hline Total & $\mathrm{N} 29$ & $\mathrm{~N} 18$ \\
\hline
\end{tabular}

Table 19 Stage based variation in Presentational tactics in Visual slides of American team

The American team starts the slide show with pairs of slides that display visual rhyming of colors and natural elements as each pair is a sequence of brown mountains followed by whitish blue lake, geyser or ocean and sky (e.g. figures 22 and 23). As in verbal utterances, there is inter-image small scale and large scale anti-thesis: on a small scale, there is Antithesis between two pictorial slides: syenite of the death valley vs. snowcapped peaks of Mount McKinley; depth of Grand Canyon vs. geysers of Yellowstone; on a large scale there exists antithesis between 
two constellations of pictorial slides: a constellation of pictures representing the beauty of natural sceneries and the repulsiveness of discarded material and people. Such inter-relation with verbal presentation depicts Intersemiotic Parallelism which further enforces the tactic of Triggering emotions.

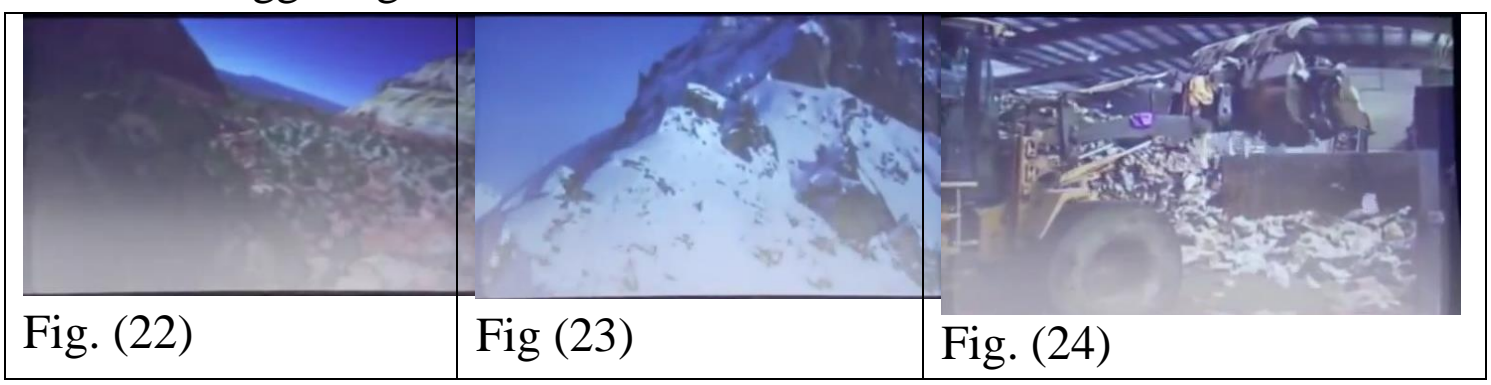

Principle of animacy is realized by representational narrative processes related to disaster to trigger sorrow, as shown in the above picture (fig. 24). As for principle of proximity it is determined by how close participants are in an image which results in feelings of intimacy or distance. What we see in American team's slides are pictures showing intimate distance: the face of a suffering mother carrying her child (fig. 25).

To arouse emotions of pity and sympathy for the Guatemalan orphans, pictures with highly saturated and contextualized naturalistic modality along with Intersemiotic Parallel Structures are displayed. For example in figure 26, we see a group of victimized children referred to in the verbal utterance: The organization houses 105 girls who have been abandoned, abused or become pregnant as victims of incest, meanwhile showing the plight of the pregnant young girl, to reflect the principle of animacy.

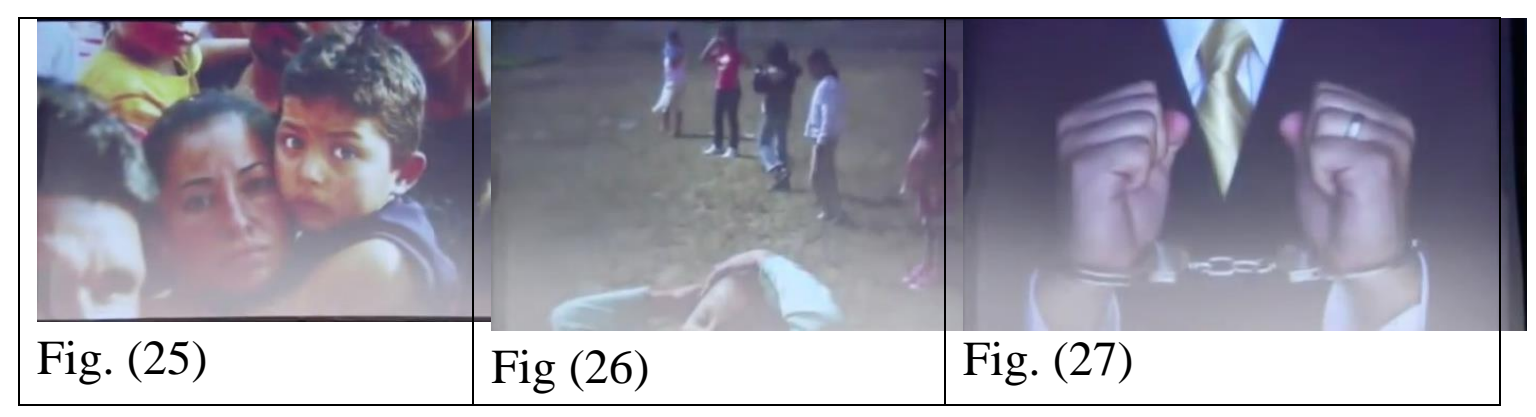


The audience gets involved by the use of frontal angle when showing the trash in the landfills or the handcuffed prisoners or the discarded victims of poverty and lack of education, to deepen sorrow and pity. Further in the evidence stage, the slides enforce Involvement by creating close social and personal distance between audience and participants, whether Guatemalan orphans or American students (figures 28 and 29).

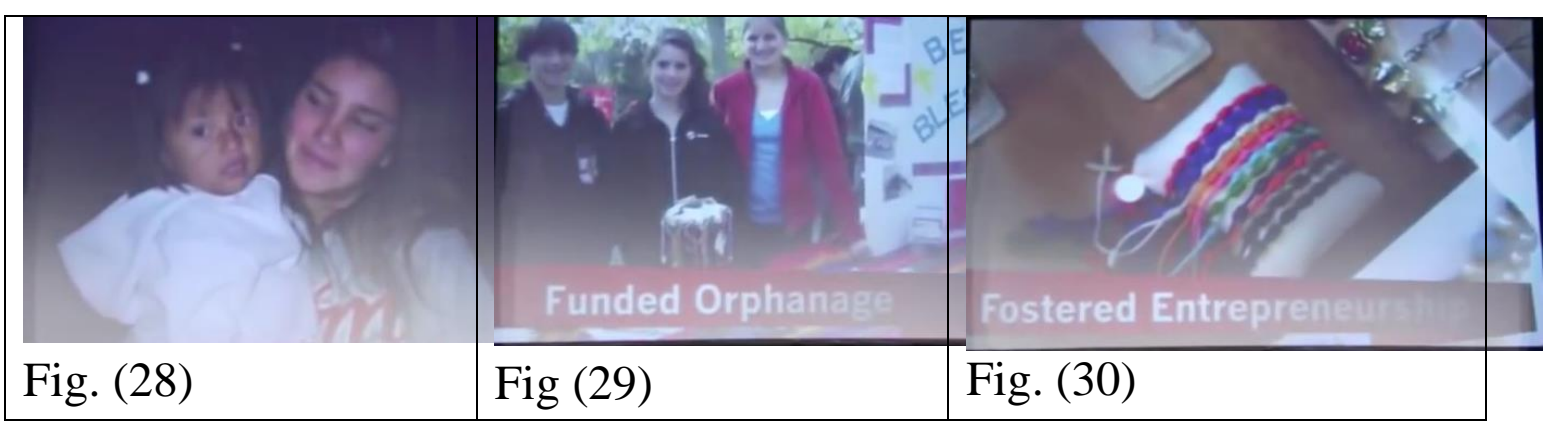

Salience, a marker of evaluation is evident in figure 30, where bracelets, the product made by the Guatemalan girls - symbol of entrepreneurship - is given prominence by their size and colour. Interestingly, collectivity is repeatedly highlighted in the American visual slides. When introducing themselves verbally, the American team members appear in a picture as one group, visually translating the We attitude and emphasizing collectivity (figure 31 ).

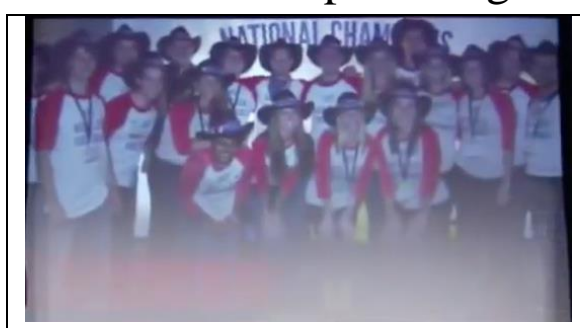

Fig. (31)

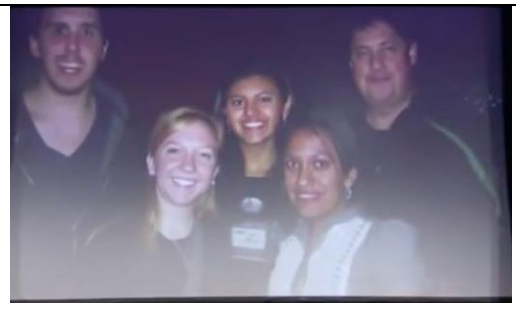

Fig (32)

In the evidence stage, the members of the team with bright smiles are pictured with the Guatemalan student enterpriser with a rather hesitant smile, indicating a sense of interdependence and willingness to help at the side of American team to soothe the fears of the Guatemalan girl (fig. 32). 


\subsubsection{Cultural Orientations:}

The presentation of the American team, in both components, tends to represent an interculture, where individualist and collectivist values are interwoven, even though the quasi-logical style has been favored. The opening stage prologue can be described as lawful magic, showing innovatively and uniquely blended use of verbal and visual rhyme, antithesis and parallel structure, which exhibits tendency to self- distinction even when triggering emotions. Most importantly is the verbal and pictorial documentation of the team's motivations, efforts, contributions, and collectivity. The team appeared as a tight group of independent individuals, working together for the interests of others rather than their own, an image reflected both verbally and visually in tactics of collectivity and principle of animacy.

While the unmarked tactics of Emphasizing Action, Logical Connection, Explicitness, and Stating Facts have dominated verbally and visually, the marked presentational tactics of Triggering Emotion, and Involvement have been extensively used to highlight the concepts of empowerment and entrepreneurship, along with the sense of ownership and self-independence. Slides have vividly and rationally verified the spoken utterances to act as clear evidence to the arguments, so that the audience have no choice but to believe what they listen to and see. As reflected in their presentation, American team has managed to reconcile collectivist values of cooperation, interdependence and group harmony with the individualist values of entrepreneurship, innovation and selfsufficiency to represent the discursive interculture of ENACTUS.

\section{Conclusion, Pedagogical Implications and Recommendations:}

As demonstrated in the analysis of ENACTUS PowerPoint presentations, a blend of individualist and collectivist orientations has been projected in the verbal and visual persuasive styles of Egyptian and American teams to verify that ENACTUS has played an effective role in building bridges between cultures through introducing new values into 
national cultures. Within the discursive interculture of ENACTUS, both teams have been encouraged to be competitive and motivated to make cultural adaptation, by merging new persuasive styles with existing ones. The Egyptian team cannot be labeled as highly collectivist since they notably adopted the marked individualist quasi-logical style; and the American team cannot be categorized as purely individualist as they innovatively employed the marked collectivist presentational style. In brief, the values of ENACTUS have mediated the influence of national 'Individualist' and 'Collectivist' cultures on the persuasion styles of the teams to the extent that Egyptian and American teams cannot be placed at the extreme ends of I-CD continuum, but rather in the middle under ENACTUS interculture:

Egypt USA

Collectivist

ENACTUS

Individualist

Cultures

Interculture

Cultures

Through extracurricular activities, ENACTUS students at tertiary levels have been successfully exposed to cross-cultural adaptation process where they are acquainted with and trained to embrace blended rhetorical styles. Pedagogically, adaptation to other cultures' persuasive styles should be extended and integrated into business and corporate communication courses to enhance university students' communicative competence and create a favorable atmosphere in culturally diverse corporates.

As PowerPoint presentations have been ubiquitous for teaching and business purposes, further research is required to correlate I-CD with para-language: prosodic features such as intonation and pitch; and body 


\section{Hala Tawfik Sorour Maklad}

language such as gestures and posture. Since ENACTUS PowerPoint presentations are pre-written and rehearsed, i.e. they are far from being spontaneous, investigating such cultural dimensions in unplanned interactions and in other business genres are highly recommended to verify or refute the findings of this study. 


\section{References}

Anderson, J. W. (1989). A comparison of Arab and American conceptions of effective persuasion. The Howard Journal of Communication. 2 (1). 81-114.

Biber, D., S. Johansson, G. Leech, S. Conrad, \& E. Finegan (2007). Longman grammar of spoken and written English. Harlow (Essex): Longman.

Brzozowska, D. \& Wladysław Chłopicki (Eds.) (2015). Culture’s software: Communication styles. Newcastle: Cambridge Scholars Publishing.

Business Dictionary. http://www.businessdictionary.com/

Carter, R. \& M. McCarthy. (2006). Cambridge grammar of English: A comprehensive guide to spoken and written English grammar and usage. Cambridge: Cambridge University Press.

Chafe, W. (1982). Integration and Involvement in Speaking, Writing, and Oral Literature. In Tannen, D. Spoken and Written Language: Exploring Orality and Literacy. Norwood: Ablex, 35-53.

Codrina C., L. (2008). The importance of individualism vs collectivism in organizational entrepreneurship. Proceedings of National and Regional Economics VII, Technical University of Kosice, Faculty of Economics. 516522.

Cole, P. \& J. Morgan (Eds.). (1975) Syntax and semantics: Speech acts. New York: Academic Press.

De Bortoli, M. \& J. Maroto. (NA). Translating colours in interactive marketing communications" retrieved March 19 2017, from http://globalpropaganda.com/articles/TranslatingColours.pdf

de Mooij, M. (2014). Human and mediated communication around the world: A comprehensive review and analysis. Springer: ChAmerican

ENACTUS. (http://enactus.org)

Feghali, E. (1997). Arab cultural communication patterns. International 


\section{Hala Tawfik Sorour Maklad}

Journal of Intercultural Relations, 21(2), 345-378.

Freed, A. F. (2015). Institutional discourse. In Karen Tracy, Cornelia Ilie, \& Todd Sandel, (Eds.) The international encyclopedia of language \& social interaction. Boston: John Wiley \& Sons. 809-826.

García-Yeste, M. (2013). Press advertisements for food in Spain: Cultural orientations and communicative style. Ibérica. 26. 195-216

Ghanem, S. \& B. Speicher (2016): Comparative persuasive styles in Arabic and English: A study of the United Nations General Assembly Debate speeches, Journal of International and Intercultural Communication, http://www.tandfonline.com/toc/rjii20/current 10.1080/17513057.2016.1219759

Grice, P. (1975). Logic and conversation. In P. Cole \& J. Morgan (Eds.), Syntax and semantics: Speech acts. New York: Academic Press. 41-58.

Gudykunst W., Y. Matsumoto, S. Ting-Toomey, T. Nishida, K. Kim, \& S. Heyman. (1996). The influence of cultural individualism-collectivism, selfconstruals, and individual values on communicative styles across cultures. Human Communication Research. 22 (4) 510-543.

Hall, E. (1981). Beyond culture. New York: Doubleday.

Harrison, C. (2003). Visual social semiotics: Understanding how still images make meaning. Technical Communication 50 (1). 46-60.

Hofstede, G. (https://geert-hofstede.com/national-culture.html)

Hofstede, G. (1991). Cultures and organizations: software of the mind. London: McGraw-Hill Book Company.

Hofstede, G. (2001). Culture's consequences: Comparing values, behaviors, institutions, and organizations across nations. Thousand Oaks: Sage Publications 
Hofstede, G. (2011). Dimensionalizing cultures: The Hofstede model in context. Online Readings in Psychology and Culture, 2(1). http://dx.doi.org/10.9707/2307-0919.1014

Hofstede, G. (2015). National differences in communication styles. In Culture's software: Communication styles (Eds.) Dorota Brzozowska \& Władysław Chłopicki. Cambridge Scholars Publishing: Newcastle. 1-14.

Kecskes, I. (2015). Intracultural Communication and Intercultural Communication: Are they different? International Review of Pragmatics 7, 171-194.

Kjeldsen, J. (2013) Virtues of visual argumentation: How pictures make the importance and strength of an argument salient. In Mohammed, D., \& Lewiński, M. (Eds.). Virtues of Argumentation. Proceedings of the 10th International Conference of the Ontario Society for the Study of Argumentation (OSSA), 22-26 May 2013. Windsor, ON: OSSA, pp. 1-13.

Kress, G. and T. van Leeuwen. (2006). Reading images: the grammar of visual design. London: Routledge.

Johnstone, B. (1989). Linguistic strategies and cultural styles for persuasive discourse. In S. Ting-Toomey \& F. Korzenny Language, Communication, and Culture: Current Directions. Newbury: Sage. 139-156.

Labov W. (1972) Language in the inner city. Philadelphia: university of Pennsylvania press.

Labov, W. (1972). The transformation of experience in narrative syntax. In W. Labov, Language in the inner city. Philadelphia: university of Pennsylvania press. 354-396.

Liu, Y. \& K. L. O'Halloran. (2009). Intersemiotic Texture: analyzing cohesive devices between language and images. Social Semiotics. 19 (4). 367-388.

Lustig M.W. \& J. Koester (2003). Intercultural competence: Interpersonal communication across cultures. Allyn and Bacon.

Mahmoud, Z. N. (1988). qiSat 3aql (Story of a Mind). Dar Al-Shorouk. Cairo 
Mohammed, D., and M. Lewiński, M. (Eds.). (2013). Virtues of argumentation. Proceedings of the 10th international conference of the Ontario society for the study of argumentation. Windsor, ON: OSSA.

Nelson, G. L., M. Al Batal \& W. El Bakry (2002). Directness vs. indirectness: Egyptian Arabic and US English communication style. International journal of intercultural relations 26. 39-57.

Niemeier S. \& R Dirven (Eds.) (1997). The Language of emotions: Conceptualization, expression, and theoretical foundation. Amsterdam: John Benjamins Publishing.

Rowley-Jolivet, E. (2004). Different visions, different visuals: A social semiotic analysis of field-specific visual composition in scientific conference presentations. Visual Communication, 3(2), 145-175.

Searle, J. R. (1979). Expression and meaning: Studies in the theory of speech acts. Cambridge: Cambridge University Press.

SIFE Team Handbook. Academic Year Ending 2012

Ting-Toomey, S. \& F. Korzenny. (1989). Language, Communication, and Culture: Current Directions. Newbury Park : Sage.

Tracy, K., C. Ilie, \& Todd Sandel, (eds.). (2015) The international encyclopedia of language \& social interaction. Boston: John Wiley \& Sons..

Ungerer, F. (1997). Emotions and emotional language in English and German news stories. In S Niemeier \& R Dirven (Eds.) The Language of emotions: Conceptualization, expression, and theoretical foundation. Amsterdam: John Benjamins Publishing. 307- 328.

van Leeuwen, T. (2005) Introducing social semiotics. London: Routledge

Yates, J., W. Orlikowski. (2007). The PowerPoint presentation and its corollaries: How genres shape communicative action in organizations. In M. Zachry and C. Thralls (eds.) Communicative practices in workplaces and 
Individualist and Collectivist Orientations in Verbal-Visual Persuasive Styles: A Study of ENACTUS PowerPoint Presentations

the professions : Cultural perspectives on the regulation of discourse and organizations. Amityville (US): Baywood Publishing Company.

Zachry M. and C. Thralls (eds.) (2007). Communicative practices in workplaces and the professions: Cultural perspectives on the regulation of discourse and organizations. Amityville (US): Baywood Publishing Company.

Zaharna, R.S. (1995). Understanding Cultural Preferences of Arab Communication Patterns. Public Relations Review. 21 (3) 241-255. 


\section{Hala Tawfik Sorour Maklad}

\section{Appendix (A)}

Transcript of Egyptian Team's Presentation

\section{Opening Stage:}

Improving lives impacting people making a difference in the world. What a splendid motive to live for. By taking the simplest action, we trigger change with an expanded effect It all starts with a small decision to begin.

Music played live by a violinist synchronized with Scriptural/Graphical Slides

\begin{tabular}{|c|c|c|c|}
\hline Slide & Verbal Phrases & $\begin{array}{l}\text { Background } \\
\text { colour }\end{array}$ & Graphics \\
\hline 1 & Begin & Grey & $\begin{array}{l}\text { A small white ball at } \\
\text { the center }\end{array}$ \\
\hline 2 & $\begin{array}{l}\text { dream to be Egypt's change } \\
\text { agent }\end{array}$ & Blue & Four balls at right \\
\hline 3 & $\begin{array}{l}\text { believe that opportunities } \\
\text { exist }\end{array}$ & Purple & A ball at top left \\
\hline 4 & $\begin{array}{l}\text { dedicate efforts to develop } \\
\text { people }\end{array}$ & Blue & A ball at bottom left \\
\hline 5 & $\begin{array}{l}\text { communicate with target } \\
\text { community }\end{array}$ & light brown & $\begin{array}{l}\text { A ball at center with } \\
\text { moving line }\end{array}$ \\
\hline 6 & pledge radical improvement & light green & $\begin{array}{l}\text { Two ball getting } \\
\text { together }\end{array}$ \\
\hline 7 & $\begin{array}{l}\text { draw customized plan and act } \\
\text { upon it }\end{array}$ & Green & $\begin{array}{l}\text { A ball at the top left } \\
\text { with Sliding line and } \\
\text { ball }\end{array}$ \\
\hline 8 & dare to defy ourselves & Blue & $\begin{array}{l}\text { The ball gets downs as } \\
\text { a parachute }\end{array}$ \\
\hline 9 & deliver valuable knowledge & Purple & $\begin{array}{l}\text { Two separated lines } \\
\text { connected with a } \\
\text { moving bridge and ball } \\
\text { moving from left to } \\
\text { right }\end{array}$ \\
\hline 10 & achieve outstanding results & Blue & $\begin{array}{l}\text { A ball at left starting a } \\
\text { half rectangular and } \\
\text { ending at right }\end{array}$ \\
\hline 11 & $\begin{array}{l}\text { rejoice in people's } \\
\text { accomplishments }\end{array}$ & Green & A ball dancing in lines \\
\hline 12 & $\begin{array}{l}\text { EMPOWERMENT/ } \\
\text { SOUND OF } \\
\text { EMPOWERMENT }\end{array}$ & Grey & $\begin{array}{l}\text { The ball rests and turns } \\
\text { into the letter 'o' of the } \\
\text { word empowerment }\end{array}$ \\
\hline
\end{tabular}


From that point, empowerment reach just gets bigger. One never knows how many lives will be impacted but someday somehow everyone will hear the sound of empowerment. The sound of empowerment, an objective we continuously strive to achieve in SIFE UFE. We always believe that empowerment is not just about providing people with what they need but it's about allowing them to develop further. Once people are empowered, they incredibly rise to create their own legacy composing their sound of empowerment With this violinist's talent revealed by simply giving him a note, he became empowered and created his own masterpiece. SIFE Universite Francis d'Egypte, SIFE UFE is proud of the sound of empowerment composed by its 121 students working for more than 35,000 hours in 13 different projects impacting the lives of 155,000 Egyptians

As you can see in our annual report all the five projects we will be presenting today completely fulfilled the five criteria and impressively generate the sound of empowerment.

\section{Evidence Stage}

Aqua Farma: Filter by nature

Give a man a fish and he will eat for a day, but teach him how to fish in $\mathrm{Al}$ Manzala Lake and he will be losing his business the very next day.

Al Manzala lake is the biggest natural lake in Egypt producing 64,000 tons of fish annually that is sufficient to feed more than 80,000 persons for a whole year, what a great resource it was!

Unfortunately since 2010 due to the increase of its water pollution rates, $48 \%$ of its marine species disappeared which led the Manzalians aqua farmers to slide to poverty to give up on their inherited business.

It was time to take action. Bring back the value of Manzala so we launched the aqua farming projects with two main objectives: to adapt new aqua farming solutions and to revive the businesses.

To adapt new aqua farming solutions, we conducted research to find the simple yet most effective filter for empowerment. Amazingly this filter is a fish, the silver carp fish.

The carp fish has exceptional advantages. It feeds entirely on marine micro creatures reducing $70 \%$ of farming expenses allocated for feeding. Additionally, being endowed with an internal filer carps control water quality. Finally this fish is considered as a good source of protein for low income consumers.

Our first action was to collaborate with a renowned expert in the aqua farming field to aware 50 farmers about the advantages of carp fish. This year 10 farmers showed deep interest in this project, we empowered them through financial, managerial and technical know how sessions. Through our several follow up visits, they shared us their calculation as reliable carp market 


\section{Hala Tawfik Sorour Maklad}

information. within one year, the aqua farmers shared 110 tons of carp worth 133,000 US dollars.

The following stage was to revive the business, we customized a financial program based on the market data. SIFE UFE started with empowering $\mathrm{Mr}$. Saeed a Manzalian Aqua Farmer with all the training needed to invest in 4 cages. This is how the financial system works; SIFE UFE provides a 1 year loan per participant, the loan covers the start up; an operational cost of the project as well as a one year monthly allowance equivalent to their Egyptian minimum wage (200 USD on the data show)

By the end of the first year, each cage produces 2.5 tons of carp for 3,300 USD. After reimbursements and taxes payment, the Aqua farmers four cages net profit will generate 4,600 USD allowing him to save 280 USD monthly and exceeding the Egyptian minimum wage by $40 \%$.

That's just for starters

For the second year, the aqua farmers will expand his business by investing in at least 1 new cage increasing his income by $195 \%$.

The sound of empowerment of the aqua farming project is exceptional.

SIFE UFE will use the reimbursements loans to empower new Manzalians creating a solid platform for a successful foundation through a sustainable chain up investment.

Aqua farming filtered by nature, we found a filtering solution for Al Manzala community, effectively reviving the businesses of 11 aqua farmers, generating revenues with 133,000 USD and built a foundation for expansion based on the customized profitable financial system. 
Appendix (B)

Transcript of American Team's Presentation

Opening Stage

From coast to coast nature's beauty surrounds our people.

From the syenite of the Death Valley to the snowcapped peaks of Mount McKinley

From the plunging depth of Grand Canyon to the rising geysers of Yellowstone From our hidden caves to ocean waves

We've been blessed with incredibly rich and diverse resources

But all of this beauty is not what we see each day

Instead we see usable material being thoughtlessly discarded in landfills slowly destroying our environment

We see people discarding their lives from lives of crime leading our nation to imprison more citizens that any other in the world

And we see people, people who have lived troubled pasts with the desire to better their futures but they return away discarded because they don't have the education or the experience to obtain employment. Our SIFE team has been moved by those discarded throughout our local and global communities.

We are SIFE USA and we are excited to share our projects with you today these projects are much more than activities we have created to help us win a competition RATHER they become the lifeblood of our members

Throughout today's presentation we will be using a three stage system to describe our projects. A primary goal for our projects is empowering others through free enterprise

Thus we don't want to be the sole element for the success of our community partners

Rather we hope to empower, educate and equip them to operate and drive on their own. In our stage one project students are serving on the frontlines focused on teaching business skills in our communities. Our stage two projects build on these relationships that we foster with community partners to move them towards self-sufficiency. Through business plan creation or administrative consulting this project involves students helping on the frontline with the main focus on developing organizational sustainability.

Finally our third stage projects are nearing a handing off point where the business of the community partner nears being self-sufficient. Although the Balmont site is always available to provide ongoing consulting our goal in phase 3 is to enable and empower the non-profit to self-manage a sustainable profitable and even scalable social enterprise on its own. 
This year our team has worked with 15 separate projects including six projects in stage 1 , seven projects in stage 2 and 2 projects in transition in stage 3. Unfortunately we only have time to discuss 4 projects with you today.

\section{Evidence Stage}

Our second project is a new project for our team. It is a stage 2 project called Be a Blessing.

In 2009, Guatemala barred all international adoptions. Unfortunately, this policy had two negative outcomes: an increasing number of children remaining in orphanages and a loss of income for so many homes depending on international adoption fees to help fund their programs. After seeing the financial struggles of these so many orphanages, Bollie Peseveney, a Guatemalan college student was determined to help. Two of our site students met Bollie on a study of broad trip where they decided to help her grow and develop her struggling social enterprise, an enterprise with good intentions but little impact.

When we started working with Bollie, she was making bracelets on her own and struggling to find ways to expand. These are some of her Guatemalan contexts. We introduced Bollie to an all-female orphanage in desperate need of funding, The Mary and Martha Orphanage. The organization houses 105 girls who have been abandoned, abused or become pregnant as victims of incest.

We worked with Bollie to develop our relationship with the nuns of the orphanage. Instead of us giving the orphanage money, we decided to involve the older girls in this enterprise to give them the sense of ownership and pride in supporting their home. The relationship with the natural thick considering the older girls who are enjoying making the bracelets during their daily craft time. Now with supplies coming from Bollie, these daily crafts would be sold with the proceeds going directly to the orphanage.

We started from the beginning. We helped Bollie set up a separate bank account and discussed how to use funds from the sale of bracelets to manage new inventory and other fees. We explained basic inventory strategies and helped create product tags to market and display the bracelets. We also discussed the importance of keeping track of sales information both for basic accounting and potential fund raising opportunities.

Understanding that Bollie had already taken a large task, we volunteered to help sell the bracelets here in the United States. We partnered with the local middle school, excited about the opportunity to sell bracelets to support the orphanage. We taught the middle schoolers basic entrepreneurial and marketing skills to sell the products. Through our local efforts, over a thousand dollars 
were raised to support the orphanage. Those funds alone fully financed the hundred and five girls for approximately three months.

Recently, we helped Bollie registered the organization as a Guatemalan NonProfit to promote donation. We also have led her through the business plan development process and helped her set up a website for her to sell the bracelets internationally. Finally, understanding that these girls are only making the bracelets for fun, during their craft time, we've considered the other groups in Guatemala that might be interested in making the bracelets as demand increases.

Through the "Be A Blessing Program", we've fostered an entrepreneurial spirit within our local and global community and kept a struggling orphanage running despite harsh economic conditions all though the power of free enterprise. 